"This is the peer reviewed version of the following article: [Organometallics 2020, 39, 1590-1601] which has been published in final form at [Link to final article using the DOI: https://dx.doi.org/10.1021/acs.organomet.9b00792]. This article may be used for noncommercial purposes in accordance with the American Chemical Society Terms and Conditions for Self-Archiving."

\title{
Carbon Dioxide Reduction by Multimetallic Uranium(IV) Complexes Supported by Redox-Active Schiff Base Ligands
}

\author{
Nadir Joria, Marta Falcone ${ }^{a}$, Rosario Scopellitia and Marinella Mazzanti*a \\ a Institut des Sciences et Ingénierie Chimiques, Ecole Polytechnique Fédérale de Lausanne (EPFL), CH-1015 Lausanne, \\ Switzerland.
}

\begin{abstract}
The synthesis, structure and the reactivity with $\mathrm{CO}_{2}$ and $\mathrm{CS}_{2}$ of new U(IV) complexes with a redox-active Schiff base are reported. The reaction of $\mathrm{UI}_{3}$ with the heptadentate Schiff base ligand 2,2',2"-tris(salicylideneimino)triethylamine (trensal) did not lead to the formation of a U(III) complex but to the reductive coupling and C-C bond formation between two imino groups of the Schiff base, yielding the U(IV) complex [ $\mathrm{U}_{2}$ (bis-trensal)], 1. Further reduction of $\mathbf{1}$ led to the dinuclear macrocyclic complex $\left[\left\{\mathrm{K}(\mathrm{THF})_{3}\right\}_{2} \mathrm{U}_{2}\right.$ (cyclo-trensal)], 3-THF, through a second $\mathrm{C}-\mathrm{C}$ bond formation reaction between two additional imino groups. Complexes $\mathbf{1}$ and $\mathbf{3}$ are oxidized by AgOTf resulting in the cleavage of the $\mathrm{C}$ - $\mathrm{C}$ bonds and leading to the formation of the U(IV) complex [U(trensal)]OTf, 2. Complex 1 does not reduce $\mathrm{CO}_{2}$ or $\mathrm{CS}_{2}$ but undergoes insertion of $\mathrm{CO}_{2}$ into one of the $\mathrm{U}-\mathrm{N}$ bonds. In contrast the reaction of $\mathbf{3}$ with 2 equivalents of $\mathrm{CO}_{2}$ leads to the reductive disproportionation of $\mathrm{CO}_{2}$ to afford carbonate in $80 \%$ yield. In the presence of a large excess of $\mathrm{CO}_{2}$ multiple reactions take place, as supported by the isolation of the crystals of $\left[\left\{\mathrm{K}(\mathrm{THF})_{3}\right\} \mathrm{U}_{2}(\mu-\mathrm{O})\left(\mathrm{CO}_{2}-\mathrm{CO}\right.\right.$-cyclo-trensal $)(\mathrm{U}($ trensal $\left.))\right]$, 4. The higher reductive activity towards $\mathrm{CO}_{2}$ of complex 3 compared to previously reported U(IV) complexes of reduced Schiff bases is interpreted in terms of its redox properties.
\end{abstract}

\section{INTRODUCTION}

Redox-active ligands which are able to participate in electron transfer processes together with the metal, are being increasingly used to expand metal reactivity and application in catalysis. ${ }^{1}$ Redox-active ligands facilitate the storage and release of electrons during substrate transformation, without involving metal oxidation state changes. In some cases, electron storage in redox-active ligand can be effected via the formation of new C-C bonds. ${ }^{2}$ Reduced uranium complexes supported by redox-active ligands, are attractive because of the high electronic flexibility that such ligands can confer to the metal center which can result in novel reactivity. ${ }^{3}$

Metal-based multi-electron transfer is accessible in uranium chemistry ${ }^{3 \mathrm{f}, 3 \mathrm{~g}, 4}$ but uncommon. In contrast, the combination of low valent uranium with redox active ligands facilitates multielectron transfer to substrates ${ }^{3 \mathrm{~g}, 5}$ which is an important requirement in the activation of small molecules such as $\mathrm{CO}_{2}$ or $\mathrm{N}_{2}$.

Notably, Bart and coworkers showed that the electrons stored in the ligand of a uranium(IV) bound pyridine(diimine) complex can effect the reductive cleavage of the azobenzene double bond ${ }^{5 a}$ and the multi electron reduction of carbonyl substrates. ${ }^{3 \mathrm{~d}}$ The same authors also showed that redox-active ligands can be used to promote the functionalization and the scission of uranyl(IV)-oxo bonds. ${ }^{6}$

However, the use of redox-active ligands to promote electron transfer in $\mathrm{f}$ elements compounds ${ }^{7}$ and in uranium chemistry ${ }^{2 e}, 5 e, 8$ in particular remains significantly rarer than in d block chemistry. ${ }^{1 a-f}$. 


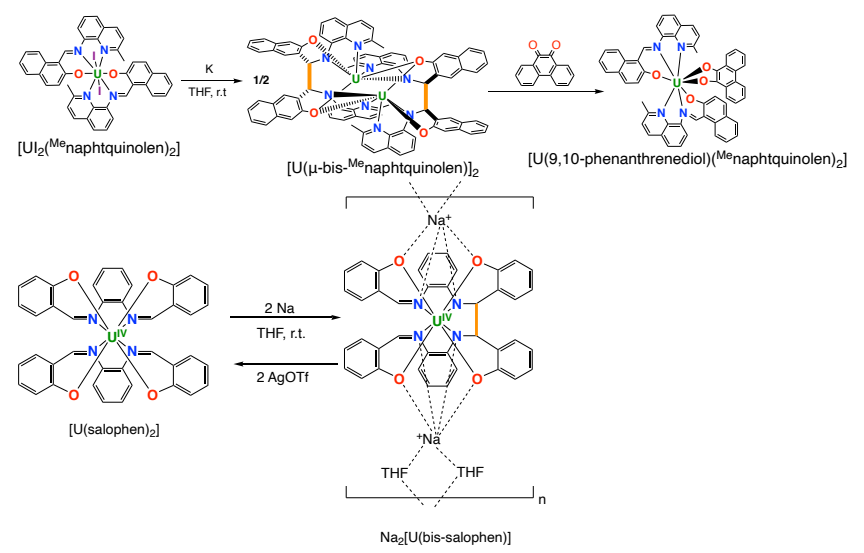

Scheme 1. The reduction of bis-Schiff base complexes of U(IV) with alkali metals leads to intermolecular (top) or intramolecular $\mathrm{C}-\mathrm{C}$ bond formation(bottom). The two electrons stored in the $\mathrm{C}-\mathrm{C}$ bonds can be used to reduce oxidizing substrates

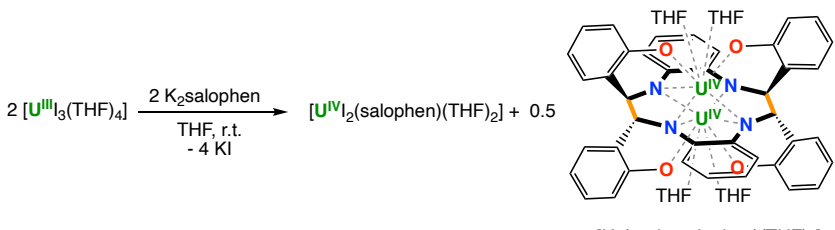

$\left[\mathrm{U}_{2}\right.$ (cyclo-salophen $\left.)(\mathrm{THF})_{4}\right]$

Scheme 2. U(III) reduces the two imino groups of the tetradentate Schiff base salophen leading to intermolecular C-C bond formation

Schiff bases were shown more than 20 years ago to act as redox-active ligands in complexes of d block elements ${ }^{9}$ leading to intramolecular or intermolecular $\mathrm{C}-\mathrm{C}$ bond formation.

In contrast, the use of Schiff base ligands in uranium chemistry was originally mostly limited to the uranyl(VI) species ${ }^{10}$ but an increasing number of U(V) ${ }^{11}$, and U(IV) Schiff base complexes has been reported in recent years. ${ }^{2 e}$, $8 a, 1213$

Our group demonstrated that Schiff bases act as redox active ligands also when combined to f block metals $\mathrm{s}^{2 \mathrm{e}, 7 \mathrm{c}, 8 \mathrm{a}}$ and to low valent uranium in particular. Notably we showed that the reduction of U(IV) complexes of tetradentate ${ }^{2 e, 12 b}$ and tridentate Schiff bases ${ }^{8 a}$ (Scheme 1) results in the reduction of the imino group of the ligand followed by formation of intermolecular or intramolecular C-C bonds. Reduction of the Schiff base imino group and formation of a new C-C bond was also observed when the Schiff base salophen (salophen: $\mathrm{N}, \mathrm{N}^{\prime}$-disalicylidene-o-phenylenediaminate) is directly reacted with an uranium(III) precursor (Scheme 2). Reactivity and electrochemical studies on Schiff base complexes of $d$ block metals suggest that the electrons stored on the ligand framework may become available for $\mathrm{CO}_{2}$ reduction. ${ }^{9 \mathrm{a}}, 14$

In contrast such reactivity has not been yet observed for Schiff base complexes of the f elements. To further explore the possibility of using electrons stored on uranium complexes of Schiff bases for the reduction of small molecules we have explored the chemistry of the heptadentate tripodal ligands 2,2',2" tris(salicylideneimino)triethylamine $\left(\mathrm{H}_{3}\right.$ trensal) with low valent uranium.
We have recently shown that the heptadentate tripodal ligand 2,2'2" $\quad$-tris(salicylideneimino)triethylamine $\left(\mathrm{H}_{3}\right.$ trensal) allows the isolation of stable complexes of uranium in oxidation states ranging from +VI to +IV. ${ }^{11 a}$ The trensal ligand can also be used to build heterobimetallic uranyl-Fe complexes. ${ }^{11 a}$

Here we show that the reaction of $\mathrm{UI}_{3}(\mathrm{THF})_{4}$ with the $\mathrm{K}_{3} \mathrm{R}$ trensal $(\mathrm{R}=\mathrm{H}$ and $\mathrm{t} B \mathrm{Bu})$ ligand results in the reduction of one imino group of the trensal ligand and in the formation of a $\mathrm{C}-\mathrm{C}$ bond between two trensal ligands affording the dimeric complexes [ $\mathrm{U}_{2}$ (bis-Rtrensal)], $\mathbf{1}$ and $\mathbf{1 a}$ (Scheme 3). Two imino groups of complex $\mathbf{1}$ can be further reduced to afford a diuranium(IV) complex supported by a macrocyclic tetra-amido-bis-imino-tetra-phenolate ligand, $\left[\left\{\mathrm{K}(\mathrm{THF})_{3}\right\}_{2} \mathrm{U}_{2}\right.$ (cyclo-trensal)], 3-THF. Complexes $\mathbf{1}$ and $\mathbf{3}$ are oxidized by AgOTf to afford [Uiv(trensal)]OTf, 2 . Complex 1 does not reduce $\mathrm{CO}_{2}$ or $\mathrm{CS}_{2}$ but undergoes insertion of $\mathrm{CO}_{2}$ into one of the $\mathrm{U}-\mathrm{N}$ bonds. In contrast complex $\mathbf{3}$ effects the reductive disproportionation of $\mathrm{CO}_{2}$ to afford carbonate. Remarkably and in contrast to the previously reported uranium complexes of redox-active Schiff base ligands, complexes 1 and 3-THF show high reactivity towards carbon dioxide and are able to promote both insertion and reduction of $\mathrm{CO}_{2}$.

\section{EXPERIMENTAL SECTION}

General Considerations Unless otherwise noted, all manipulations were carried out at ambient temperature under an inert argon atmosphere using Schlenk techniques and an MBraun glovebox equipped with a purifier unit. The water and oxygen levels were always kept at less than 1 $\mathrm{ppm}$. Glassware was dried overnight at $140^{\circ} \mathrm{C}$ before use.

NMR experiments were carried out using NMR tubes adapted with J. Young valves. ${ }^{1} \mathrm{H},{ }^{19} \mathrm{~F}$ and ${ }^{13} \mathrm{C}\left\{{ }^{1} \mathrm{H}\right\}$ NMR spectra were recorded on a Bruker 400 or $600 \mathrm{MHz}$ spectrometers. NMR chemical shifts are reported in ppm with solvent as internal reference.

Mass spectrometry was performed on a LTQ Orbitrap FTMS instrument (LTQ Orbitrap Elite FTMS, Thermo Scientific, Bremen, Germany) operated in the positive mode coupled with a robotic chip-based nano-ESI source (TriVersa Nanomate, Advion Biosciences, Ithaca, NY, U.S.A.). A standard data acquisition and instrument control system was utilized (Thermo Scientific), whereas the ion source was controlled by Chipsoft 8.3.1 software (Advion BioScience). The experimental conditions for the ionization voltage was $+5.8 \mathrm{kV}$ and the gas pressure was set at $0.30 \mathrm{psi}$. The temperature of ion transfer capillary was $275^{\circ} \mathrm{C}$. Data were analyzed using XCalibur (Thermo Scientific) and MS tools available at http://ms.cheminfo.org.

Electrochemical Methods. Cyclic Voltammetry experiments were carried out at room temperature in an argon-filled glovebox described above. Data were collected using a Biologic SP-300 potentiostat connected to a personal computer. All samples were $4 \mathrm{mM}$ in complex with $0.1 \mathrm{M}\left[\mathrm{Bu}_{4} \mathrm{~N}\right]\left[\mathrm{PF}_{6}\right]$ supporting electrolyte in pyridine or THF solution. The experiments were carried out with a platinum disk $(\mathrm{d}=5 \mathrm{~mm})$ working electrode, a platinum wire counter electrode, and an $\mathrm{Ag} / \mathrm{AgCl}$ reference electrode. The experiments were repeated on independently synthesized samples to assess the reproducibility of the measurement. 
Potential calibration was performed at the end of each data collection cycle using the ferrocene/ferrocenium $\left[\left(\mathrm{C}_{5} \mathrm{H}_{5}\right)_{2} \mathrm{Fe}\right]^{+/ 0}$ couple as an internal standard.

The UV-Visible spectra were recorded as $5 \mathrm{mM}$ solutions in THF using $1 \mathrm{~mm}$ cuvettes equipped with a J-Young valve and a Perkin Elmer 950 spectrometer.

Elemental analyses were performed using a Thermo Scientific Flash 2000 Organic Elemental Analyzer at the Institut of Chemistry and Chemical Engineering at EPFL.

Starting materials Unless otherwise noted, reagents were purchased from commercial suppliers and used without further purification. The solvents were purchased from Aldrich or Cortecnet (deuterated solvents) in their anhydrous form, conditioned under argon and vacuum distilled from $\mathrm{K} /$ benzophenone (toluene, hexane, pyridine and THF). Depleted uranium was purchased from Ibilabs, Florida, USA. The ligands $\mathrm{H}_{3}$ trensal, $^{15} \mathrm{~K}_{3}$ trensal $^{11 \mathrm{a}}$ and $\mathrm{H}_{3}{ }^{\mathrm{t} B u}$-trensal (tris[4-(2-hydroxy-3-tert-butylphenyl)-3aza-3-butenyl]amine), ${ }^{16} \mathrm{UI}_{3}(\mathrm{THF})_{4},{ }^{17} \mathrm{UCl}_{4}{ }^{18}$ and $\mathrm{UI}_{4}\left(\mathrm{OEt}_{2}\right)_{2}{ }^{19}$ were prepared according to the published procedures. ${ }^{13} \mathrm{CO}_{2}\left(93.13 \%{ }^{13} \mathrm{C}\right)$ was purchased from Cortecnet and transferred prior to use in a flask in equipped with a Young valve and containing activated 3 Å molecular sieves.

Caution: Depleted uranium (primary isotope ${ }^{238} \mathrm{U}$ ) is a weak $\alpha$-emitter $(4.197 \mathrm{MeV})$ with a half-life of $4.47 \times 10^{9}$ years. Manipulations and reactions should be carried out in monitored fume hoods or in an inert atmosphere glovebox in a radiation laboratory equipped with $\alpha$ - and $\beta$-counting equipment.

Synthesis $K_{3}{ }^{t} B u$-trensal. A white suspension of potassium hydride (44.4 mg, $1.11 \mathrm{mmol}, 3.2$ equiv) in THF ( $0.8 \mathrm{~mL})$ was added to a yellow solution of tBu-trensal $(275.2 \mathrm{mg}$, $0.3461 \mathrm{mmol}, 1$ equiv) in THF (3.0 mL) and the resulting reaction mixture was left stirring at room temperature overnight. The resulting suspension was filtered to yield a yellow solution. The latter was dried and washed twice with hexane (1.0 mL each) to afford $\mathrm{K}_{3}{ }^{\mathrm{t}} \mathrm{Bu}$-trensal as a pale yellow powder $(272.5 \mathrm{mg}, 85.8 \%$ yield).

Anal. Calcd for $\mathrm{K}_{3}{ }^{t} \mathrm{Bu}$-trensal(Hexane) ${ }_{0.1} \mathrm{C}_{54.6} \mathrm{H}_{76.4} \mathrm{~N}_{4} \mathrm{O}_{3}$ : C, $67.51 \%$; H, 8.39\%; N, 6.10\%. Found: C, 66.98\%; H, 8.83\%; N, $5.66 \%$

${ }^{1} \mathrm{H}$ NMR (400 MHz, pyr- $\left.\mathrm{d}_{5}, 298 \mathrm{~K}\right): \delta=1.51(\mathrm{~s}, 27 \mathrm{H}), 1.77$ (s, 27H), 2.63 (s, 6H), 3.59 (s, 6H), $3.71(\mathrm{~s}, 3 \mathrm{H}), 7.65(\mathrm{~s}, 3 \mathrm{H}), 8.47$ (s, 3H).

${ }^{13} \mathrm{C}\left\{{ }^{1} \mathrm{H}\right\}$ NMR $(100 \mathrm{MHz}$, pyr-d $5,298 \mathrm{~K}): \delta=30.41,32.04$, $33.69,35.68$, 58.28, 60.33, 121.32, 126.14, 129.43, 141.00, $169.14,171.17$.

Synthesis [ $U_{2}$ (bis-trensal)], 1. A white suspension of $\mathrm{K}_{3}$ trensal (57.0 mg, $0.0911 \mathrm{mmol} 1$ equiv) in THF (1.2 mL) was added to a blue solution of $\mathrm{UI}_{3}(\mathrm{THF})_{4}(82.7 \mathrm{mg}, 0.0912$ mmol 1 equiv) in THF $(1.0 \mathrm{~mL})$ (Figure 1). The mixture turned immediately orange and KI precipitated out of the solution. The reaction mixture was filtered, yielding a dark orange filtrate. Slow diffusion of hexane into the orange solution gave [ $\mathrm{U}_{2}$ (bis-trensal)(THF)], complex $\mathbf{1}$, as a pale orange powder ( $88.5 \mathrm{mg}, 66.6 \%$ yield) . ${ }^{1} \mathrm{H}$ NMR $(400 \mathrm{MHz}$, THF- $\left.\mathrm{d}_{8}, 298 \mathrm{~K}\right): \delta=-66.01(\mathrm{~s}, 1 \mathrm{H}),-52.07(\mathrm{~s}, 1 \mathrm{H}),-45.32(\mathrm{~s}$, $1 \mathrm{H}),-37.74(\mathrm{~s}, 1 \mathrm{H}),-34.61(\mathrm{~s}, 1 \mathrm{H}),-32.17(\mathrm{~s}, 1 \mathrm{H}),-30.69(\mathrm{~s}$, $1 \mathrm{H}),-20.46(\mathrm{~s}, 1 \mathrm{H}),-16.69(\mathrm{~s}, 1 \mathrm{H}),-13.44(\mathrm{~s}, 1 \mathrm{H}),-5.76(\mathrm{~s}$, $1 \mathrm{H}),-4.92(\mathrm{~s}, 1 \mathrm{H}),-2.36(\mathrm{~s}, 1 \mathrm{H}),-0.11(\mathrm{~s}, 1 \mathrm{H}), 0.70(\mathrm{~s}, 1 \mathrm{H})$, 13.66 (s, 1H), 15.70 (s, 1H), 23.15 (s, 1H), 23.92 (s, 1H), $24.68(\mathrm{~s}, 1 \mathrm{H}), 26.52(\mathrm{~s}, 1 \mathrm{H}), 35.75(\mathrm{~s}, 1 \mathrm{H}), 38.05(\mathrm{~s}, 1 \mathrm{H})$, $41.81(\mathrm{~s}, 1 \mathrm{H}), 46.26(\mathrm{~s}, 1 \mathrm{H}), 63.27(\mathrm{~s}, 1 \mathrm{H})$. Anal. Calcd for [U $\mathrm{U}_{2}$ (bis-trensal)](THF) $\mathrm{C}_{58} \mathrm{H}_{62} \mathrm{~N}_{8} \mathrm{O}_{7} \mathrm{U}_{2}: \mathrm{C}, 47.74 ; \mathrm{H}, 4.28 ; \mathrm{N}$, 7.68. Found: C, 48.12; H, 4.55; N, 7.38. Crystallization trials were unsuccessful.

UV-Vis (THF) $\lambda_{\max }: 275 \mathrm{~nm}, \varepsilon=9324 \mathrm{M}^{-1} . \mathrm{cm}^{-1}, \lambda_{\max }: 290$ $\mathrm{nm}, \varepsilon=9589 \mathrm{M}^{-1} . \mathrm{cm}^{-1}, \lambda_{\max }: 360 \mathrm{~nm}, \varepsilon=8567 \mathrm{M}^{-1} . \mathrm{cm}^{-1}$

Complete removal of KI from 1 is difficult and in large synthesis small amount of KI may remain leading to the presence of KI in the synthesis of complexes $\mathbf{2}$ and $\mathbf{3}$.

Isolation of crystals of $\left[U_{2}\left(\right.\right.$ bis- $^{-} B$ Bu-trensal)], $1 \boldsymbol{a}$. The compound 1a was isolated following the procedure used for 1 , by adding a white suspension of $\mathrm{K}_{3}$-tBu-trensal $(50.0 \mathrm{mg}$, $0.0550 \mathrm{mmol}, 1$ equiv) in THF (1 mL) to a blue solution of $\mathrm{UI}_{3}(\mathrm{THF})_{4}(50.0 \mathrm{mg}, 0.0551 \mathrm{mmol}, 1$ equiv) in THF $(1 \mathrm{~mL})$. Slow diffusion of hexane or toluene into the reaction mixture yielded brown crystals of [ $\mathrm{U}_{2}$ (bis-t $\mathrm{Bu}$-trensal)], $\mathbf{1 a}$. Isolation of analytically pure complex $\mathbf{1 a}$ is not reproducible because of the presence of side products that can cocrystallize with 1a. The proton NMR of the isolated compound is given in the Figure S4.

Synthesis [U(trensal)][OTf], 2. To an orange solution of complex 1 (18.7 mg, $0.0134 \mathrm{mmol}, 1$ equiv) in THF (1 mL), 2 equivalents of solid AgOTf ( $6.9 \mathrm{mg}, 0.027 \mathrm{mmol}$, 2 equiv) were added. The reaction mixture turned immediately dark brown. The mixture was filtered to eliminate $\mathrm{Ag}(0)$. Single crystals suitable for X-ray diffraction, of the triflate anion complex [U(trensal)]OTf, 2 were obtained by slow diffusion of toluene into a THF reaction mixture (16.4 mg, 70\% yield). Anal. Calcd for [U(trensal)](OTf).(KI) 0.15 $\mathrm{C}_{28} \mathrm{H}_{27} \mathrm{~N}_{4} \mathrm{O}_{6} \mathrm{U}_{1} \mathrm{~F}_{3} \mathrm{~S}_{1} \cdot(\mathrm{KI})_{0.15}$ : C: $38.77 \%$; $\mathrm{H}: 3.14 \%$; N: 6.46\%. Found: C: $39.2 \%$; H: 3.49\%; N: 5.78\%.

${ }^{1} \mathrm{H}$ NMR $\left(400 \mathrm{MHz}, \mathrm{THF}-\mathrm{d}_{8}, 298 \mathrm{~K}\right): \delta=-8.65(\mathrm{~s}, 6 \mathrm{H}), 2.76(\mathrm{~s}$, 6H), 5.33 (s, 3H), 8.61 (s, 3H), 10.61 (s, 3H), 13.19 (s, 3H), 34.87 (s, 3H).

${ }^{19} \mathrm{~F}$ NMR (376.5 MHz, THF-d $8,298 \mathrm{~K}$ ): $\delta=-83.26$ (free OTf)

UV-Vis (THF) $\lambda_{\text {max }}: 275 \mathrm{~nm}, \varepsilon=9029 \mathrm{M}^{-1} . \mathrm{cm}^{-1}, \lambda_{\max }: 290$

$\mathrm{nm}, \varepsilon=9059 \mathrm{M}^{-1} . \mathrm{cm}^{-1}, \lambda_{\max }: 360 \mathrm{~nm}, \varepsilon=8284 \mathrm{M}^{-1} . \mathrm{cm}^{-1}$

Reaction of [ $\mathrm{U}_{2}$ (bis-trensal)] with $\mathrm{CO}_{2}$. An orange solution of complex 1 (16.2 mg, 0.006 mol, 1 equiv) in THF-d 8 ( $0.5 \mathrm{~mL})$ was degassed by freeze-pump-thawing and then an excess (1 atm) of $\mathrm{CO}_{2}$ was added. The ${ }^{1} \mathrm{H}$ NMR spectrum of the crude mixture shows the disappearance of the starting material within six days. After six days an orange powder representing the $62 \%$ of the initial mass $(10.1 \mathrm{mg}$ of powder) is formed. The proton NMR spectrum of the pale orange solution obtained after removal of the precipitate shows a new set of signals. ${ }^{1} \mathrm{H}$ NMR of the reaction mixture (400 MHz, pyr- $\left.\mathrm{d}_{5}, 298 \mathrm{~K}\right): \delta=-60.72(\mathrm{~s}, 1 \mathrm{H}),-57.64(\mathrm{~s}, 1 \mathrm{H})$, $-56.63(\mathrm{~s}, 1 \mathrm{H}),-53.62(\mathrm{~s}, 1 \mathrm{H}),-45.18(\mathrm{~s}, 1 \mathrm{H}),-41.64(\mathrm{~s}, 1 \mathrm{H})$, $-41.43(\mathrm{~s}, 1 \mathrm{H}),-41.02(\mathrm{~s}, 1 \mathrm{H}),-25.20(\mathrm{~s}, 1 \mathrm{H}),-21.38(\mathrm{~s}, 1 \mathrm{H})$, $-10.88(\mathrm{~s}, 1 \mathrm{H}),-10.70(\mathrm{~s}, 1 \mathrm{H}),-10.48(\mathrm{~s}, 1 \mathrm{H}),-9.68(\mathrm{~s}, 1 \mathrm{H})$, 
$-8.33(\mathrm{~s}, 1 \mathrm{H}),-6.98(\mathrm{~s}, 1 \mathrm{H}),-5.93(\mathrm{~s}, 1 \mathrm{H}),-3.66(\mathrm{~s}, 1 \mathrm{H}),-3.39$ $(\mathrm{s}, 1 \mathrm{H}),-2.78(\mathrm{~s}, 1 \mathrm{H}),-2.60(\mathrm{~s}, 1 \mathrm{H}),-1.47(\mathrm{~s}, 1 \mathrm{H}),-0.02(\mathrm{~s}$, $1 \mathrm{H}), 0.38(\mathrm{~s}, 1 \mathrm{H}), 1.34(\mathrm{~s}, 1 \mathrm{H}), 2.54(\mathrm{~s}, 1 \mathrm{H}), 6.78(\mathrm{~s}, 1 \mathrm{H}), 7.49$ $(\mathrm{s}, 1 \mathrm{H}), 7.88(\mathrm{~s}, 1 \mathrm{H}), 8.03(\mathrm{~s}, 1 \mathrm{H}), 8.41(\mathrm{~s}, 1 \mathrm{H}), 9.07(\mathrm{~s}, 1 \mathrm{H})$, $9.89(\mathrm{~s}, 1 \mathrm{H}), 12.63(\mathrm{~s}, 1 \mathrm{H}), 12.94(\mathrm{~s}, 1 \mathrm{H}), 13.12(\mathrm{~s}, 1 \mathrm{H}), 15.79$ $(\mathrm{s}, 1 \mathrm{H}), 16.79(\mathrm{~s}, 1 \mathrm{H}), 17.36(\mathrm{~s}, 1 \mathrm{H}), 18.85(\mathrm{~s}, 1 \mathrm{H}), 22.57(\mathrm{~s}$, $1 \mathrm{H}), 22.96$ (s, 1H), 23.15 (s, 1H), $25.96(\mathrm{~s}, 1 \mathrm{H}), 26.61(\mathrm{~s}, 1 \mathrm{H})$, 27.39 (s, 1H), $30.03(\mathrm{~s}, 1 \mathrm{H}), 30.81(\mathrm{~s}, 1 \mathrm{H}), 37.68(\mathrm{~s}, 1 \mathrm{H})$, $40.49(\mathrm{~s}, 1 \mathrm{H}), 60.12(\mathrm{~s}, 1 \mathrm{H}), 70.66$ (s, 1H). ESI-MS: $\mathrm{m} / \mathrm{z}=1431.6\left(\left[\mathrm{U}_{2} \text { (bis-trensal) }\left(\mathrm{CO}_{2}\right)\right]^{+}\right)$.

The reaction performed with different stoichiometries of ${ }^{13} \mathrm{CO}_{2}(2,10$ and 100 equiv) shows only different reaction rates, but in all cases the ${ }^{1} \mathrm{H}$ and ${ }^{13} \mathrm{C}$-NMR spectra of the supernatant were the same. ${ }^{1} \mathrm{H}$ NMR (400 MHz, THF-d8, 298 K): $\delta=-71.53,-63.4,-62.5,-56.3,-49.77,-49.10,-44.20$, 42.35, -36. 87, -34.27, -21.02, -15.91, -15.5, -11.6, -11.3, $9.53,-7.89,-5.63,-5.06,-4.64,-2.03,-1.33,0.88,2.10,2.23$, $4.98,8.00,8.32,10.03,10.48,13.48,15.22,15.44,16.67$, $18.01,21.95,23.26,24.29,24.52,26.70,28.37,29.04,29.39$, $32.23,35.99,36.71,38.52,40.09,65.88,88.89 .{ }^{13} \mathrm{C}\left\{{ }^{1} \mathrm{H}\right\} \mathrm{NMR}$ $\left(100 \mathrm{MHz}, \mathrm{THF}-\mathrm{d}_{8}, 298 \mathrm{~K}\right): \delta=202(\mathrm{C}=0) .{ }^{1} \mathrm{H}$ NMR $(400 \mathrm{MHz}$, pyr- $\left.\mathrm{d}_{5}, 298 \mathrm{~K}\right): \delta=-60.72,-57.64,-56.63,-53.62,-45.18$, $43.17,-41.64,-41.43,-41.02,-25.50,-21.38,-10.88$, $10.70,-9.68,-8.33,-6.98,-5.93,-3.66,-3.39,-2.78,-2.60$, $-1.47,-0.02,1.34,2.54,6.78,7.88,8.03,8.41,9.07,9.89$, $12.94,13.1215 .79,16.79,17.36,18.85,22.57,22.9623 .15$, 25.96, 26.61, 27.39, 30.03, 36.81, 37.68, 40.49, 60.12, 70.80, ${ }^{13} \mathrm{C}\left\{{ }^{1} \mathrm{H}\right\}$ NMR (100 MHz, pyr-d $\left.\mathrm{d}_{5}, 298 \mathrm{~K}\right): \delta=190.8(\mathrm{C}=0)$

${ }^{13} \mathrm{C}\left\{{ }^{1} \mathrm{H}\right\}$ NMR $\left(100 \mathrm{MHz}, \mathrm{D}_{2} \mathrm{O}, 298 \mathrm{~K}\right): \delta=162.5(\mathrm{NC}=0) ; \delta=$ 178.1 assigned to carbamate and its hydrolysis product.

Removal of the solvent from the supernatant afforded a brown solid. Anal. Calcd for [ $\mathrm{U}_{2}$ (bistrensal) $\left.\left(\mathrm{CO}_{2}\right)\right](\mathrm{THF}) \cdot(\mathrm{KI})_{0.25} \mathrm{C}_{55} \mathrm{H}_{54} \mathrm{~N}_{8} \mathrm{O}_{8} \mathrm{U}_{2} \bullet(\mathrm{THF})(\mathrm{KI})_{0.25} \mathrm{C}$ : 45.87\%; H: 4.05 \%; N: 7.25\%. Found: C: 46.02\%; H: 4.45\%; $\mathrm{N}: 6.81 \%$.

The orange powder from the reaction mixture dissolves in pyridine and shows several signals in the carbon NMR, suggesting the presence of $\left[\mathrm{U}_{2}\right.$ (bis-trensal) $\left.\left(\mathrm{CO}_{2}\right)\right]$ and of additional insertion products ${ }^{13} \mathrm{C}\left\{{ }^{1} \mathrm{H}\right\} \mathrm{NMR}\left(100 \mathrm{MHz}, \mathrm{D}_{2} \mathrm{O}\right.$, $298 \mathrm{~K}): \delta=162.5(\mathrm{C}=0) ; 164.5(\mathrm{C}=0) ; 169.2(\mathrm{C}=0)$.

Dissolution of the powder or supernatant in $\mathrm{D}_{2} \mathrm{O}(\mathrm{pD}=12)$ does not show the presence of $\mathrm{CO}_{2}$ reduction products, such as oxalate or carbonate.

Synthesis of $\left[\mathrm{K}_{2} \mathrm{U}_{2}\right.$ (cyclo-trensal)], 3. To an orange solution of complex 1 (26.2 mg, 0.019 mmol, 1 equiv) in THF ( $1 \mathrm{~mL}$ ), 2 equivalents of $\mathrm{KC}_{8}(5.3 \mathrm{mg}, 0.039 \mathrm{mmol}, 2$ equiv) were added. The resulting dark brown reaction mixture was filtered to afford a brown solution. The ${ }^{1} \mathrm{H}$ NMR spectrum of the solution did not show any signal. Upon slow diffusion of hexane into the solution, complex $\left[\left\{\mathrm{K}(\mathrm{THF})_{3}\right\}_{2} \mathrm{U}_{2}\right.$ (cyclo-bistrensal)], 3-THF could be isolated as a brown powder (19.6 mg, $65 \%$ yield). Anal. Calcd for $\left[\mathrm{K}_{2} \mathrm{U}_{2}\right.$ (cyclotrensal)](THF) •(KI) $0.25 \quad \mathrm{C}_{54} \mathrm{H}_{54} \mathrm{~N}_{8} \mathrm{O}_{6} \mathrm{U}_{2} \cdot(\mathrm{THF})(\mathrm{KI})_{0.25}: \quad \mathrm{C}$ : 44.12\%; H: 3.96 \%; N: 7.10\%. Found: C: 44.49\%; H: 4.25\%; $\mathrm{N}: 6.68 \%$.

UV-Vis (THF) $\lambda_{\max }: 275 \mathrm{~nm}, \varepsilon=9529 \mathrm{M}^{-1} . \mathrm{cm}^{-1}, \lambda_{\max }: 290$ $\mathrm{nm}, \varepsilon=9020 \mathrm{M}^{-1} . \mathrm{cm}^{-1}, \lambda_{\max }: 360 \mathrm{~nm}, \varepsilon=8341 \mathrm{M}^{-1} . \mathrm{cm}^{-1}$

Single crystals suitable for $\mathrm{X}$-ray diffraction of $\left[\left\{\mathrm{K}(\mathrm{Py})_{3}\right\}_{2} \mathrm{U}_{2}\right.$ (cyclo-trensal)], 3-py, were obtained by slow diffusion of toluene into a pyridine solution of 3-THF.
Reaction of $\left[\left\{\mathrm{K}(\mathrm{THF})_{3}\right\}_{2} \mathrm{U}_{2}\right.$ (cyclo-trensal)], 3-THF with 2 eq of AgOTf. A brown solution of complex 3-THF (5.0 mg, 0.0026 mmol, 1 equiv) in THF ( $0.5 \mathrm{~mL}$ ) was added to solid AgOTf ( $1.4 \mathrm{mg}, 0.054 \mathrm{mmol}, 2$ equiv). The reaction mixture turned immediately dark orange. The mixture was filtered to eliminate $\mathrm{Ag}(0)$. The ${ }^{1} \mathrm{H}$ NMR (THF- $\mathrm{d}_{8}, 400 \mathrm{MHz}, 298 \mathrm{~K}$ ) spectrum of the dark orange solution shows only the signals assigned to complex $\mathbf{1}$.

Reaction of $\left[\left\{\mathrm{K}(\mathrm{THF})_{3}\right\}_{2} \mathrm{U}_{2}\right.$ (cyclo-trensal)], 3-THF with 4 eq of AgOTf. A brown solution of complex 3-THF (8.1 mg, 0.0055 mmol, 1 equiv) in THF ( $1 \mathrm{~mL}$ ) was added to solid AgOTf (5.7 $\mathrm{mg}, 0.022 \mathrm{mmol}, 4$ equiv). The reaction mixture turned immediately dark brown. The mixture was filtered to eliminate $\mathrm{Ag}(0)$. The ${ }^{1} \mathrm{H}$ NMR (THF- $\mathrm{d}_{8}, 400 \mathrm{MHz}, 298 \mathrm{~K}$ ) spectrum of the dark brown solution shows only the signals assigned to complex 2 .

Reaction of $\left[\left\{\mathrm{K}(\mathrm{THF})_{3}\right\}_{2} \mathrm{U}_{2}\right.$ (cyclo-trensal)], 3-THF with ${ }^{13} \mathrm{CS}_{2}$. Complex 3-THF was prepared in situ from the reduction of [U $\mathrm{U}_{2}$ (bis-trensal)] ( $8.3 \mathrm{mg}, 0.006 \mathrm{mmol}, 1$ equiv) in THF $(0.5$ $\mathrm{mL})$ with a suspension of $\mathrm{KC}_{8}(1.7 \mathrm{mg}, 0.0126 \mathrm{mmol}, 2$ equiv) in THF ( $0.3 \mathrm{~mL})$. After removal of $\mathrm{KI}$, all volatiles were removed in vacuo from the resulting brown solution of 3THF. The brown solid was dissolved in THF-d $8(0.7 \mathrm{~mL})$ and ${ }^{13} \mathrm{CS}_{2}(1.4 \mu \mathrm{l}, 0.023 \mathrm{mmol}, 4$ equiv) was added. Upon addition of $\mathrm{CS}_{2}$ a dark orange suspension is formed. After two days, a pale orange powder comes down and a dark orange supernantant is formed. The ${ }^{1} \mathrm{H}$ NMR spectrum of the solution taken shows only the signals assigned to complex 1, and the ${ }^{13} \mathrm{C}\left\{{ }^{1} \mathrm{H}\right\}$ NMR spectrum (THF-d $8,100 \mathrm{MHz}, 298 \mathrm{~K}$ ) shows three peaks at $128.97 \mathrm{ppm}$ (new species), 193.56 ppm (free ${ }^{13} \mathrm{CS}_{2}$ ) and $248.71 \mathrm{ppm}$ (new species). After removing the solvent and dissolving the residue in DMSO$\mathrm{d}_{6}$, the ${ }^{1} \mathrm{H}$ NMR spectrum shows the signals assigned to complex 1 and the ${ }^{13} \mathrm{C}$ NMR spectrum (DMSO-d6, $100 \mathrm{MHz}$, $298 \mathrm{~K})$ shows peaks at $145.01 \mathrm{ppm}, 203.57 \mathrm{ppm}\left({ }^{13} \mathrm{C}_{2} \mathrm{~S}_{5}{ }^{-2}\right)$, $263.88 \mathrm{ppm}\left({ }^{13} \mathrm{C}_{2} \mathrm{~S}_{4}{ }^{-2}\right)$ and $266.92 \mathrm{ppm}\left({ }^{13} \mathrm{CS}_{3}{ }^{-2}\right)$ assigned to $\mathrm{CS}_{2}$ reduction products. ${ }^{20}$

\section{Reaction of [ $\left[\mathrm{K}(\mathrm{THF})_{3}\right\}_{2} \mathrm{U}_{2}$ (cyclo-trensal)], 3-THF with $\mathrm{CO}_{2}$ Reaction of 3-THF with 1, 2, 4, 100 equiv. of ${ }^{13} \mathrm{CO}_{2}$}

Complex 3-THF was prepared in situ from the reduction of [U $\mathrm{U}_{2}$ (bis-trensal)] (9.4 mg, $0.068 \mathrm{mmol}, 1$ equiv) in THF (0.6 $\mathrm{mL})$ with a suspension of $\mathrm{KC}_{8}(1.9 \mathrm{mg}, 0.0140 \mathrm{mmol}, 2$ equiv) in THF (0.2 mL). After removal of $\mathrm{KI}$, the resulting brown solution of 3-THF was degassed by freeze-pumpthawing and 2 eq of ${ }^{13} \mathrm{CO}_{2}$ were added. The ${ }^{1} \mathrm{H}$ NMR spectrum of the reaction mixture taken immediately after addition of 2 equiv. of ${ }^{13} \mathrm{CO}_{2}$ show only signals assigned to complex 1.

The reaction was repeated in similar manner for 1,4 and 100 equiv. of ${ }^{13} \mathrm{CO}_{2}$. The ${ }^{1} \mathrm{H}$ NMR spectrum of the reaction mixture taken immediately after addition of 4 equiv. of ${ }^{13} \mathrm{CO}_{2}$ shows only signals assigned to complex 1, but after 4 days signals assigned to insertion products are observed.

After 7 days, the ${ }^{13} \mathrm{C}\left\{{ }^{1} \mathrm{H}\right\}$ NMR spectrum of all the reaction mixtures (THF-d $, 151 \mathrm{MHz}, 298 \mathrm{~K}$ ) shows only the signal at $\delta=125.0 \mathrm{ppm}$ of free ${ }^{13} \mathrm{CO}_{2}$. Upon removal of the solvent in vacuo and after dissolution in basic $\mathrm{D}_{2} \mathrm{O}(\mathrm{pD}=12)$, 
quantitative ${ }^{13} \mathrm{C}\left\{{ }^{1} \mathrm{H}\right\}$ NMR experiments were performed $\left({ }^{13} \mathrm{C}\right.$-labelled sodium acetate as reference).

The yields in carbonate correspond to $79.5 \%, 80,6 \% .78 .2 \%$ and $91.2 \%$ (calculated with respect to the value expected if only two molecules of $\mathrm{CO}_{2}$ react with 3 ) when $1,2,4$ and 100 equiv. of ${ }^{13} \mathrm{CO}_{2}$ are added per dinuclear complex, respectively.

${ }^{13} \mathrm{C}\left\{{ }^{1} \mathrm{H}\right\}$ NMR experiments carried out after quenching in basic $\mathrm{D}_{2} \mathrm{O}(\mathrm{pD}=12)$ the reaction mixture after addition of 100 equivalents of $\mathrm{CO}_{2}$ shows in addition to the signals assigned to carbonate signals at $162.45 \mathrm{ppm}$ and 162.31 ppm assigned to insertion products.

\section{Reaction of 3-THF with 1atm $\mathrm{CO}_{2}$}

Complex 3-THF was prepared in situ from the reduction of [ $\mathrm{U}_{2}$ (bis-trensal)] ( $30.9 \mathrm{mg}, 0.022 \mathrm{mmol}, 1$ equiv) in THF (1 $\mathrm{mL})$ with a suspension of $\mathrm{KC}_{8}(6.0 \mathrm{mg}, 0.044 \mathrm{mmol}, 2$ equiv $)$ in THF (1.0 mL). After removal of KI, the resulting brown solution of 3-THF was degassed by freeze-pump-thawing and $1 \mathrm{~atm}$ of $\mathrm{CO}_{2}$ was added. Upon addition of $\mathrm{CO}_{2}$ the solution turned from brown to colorless and an orange precipitate appeared within 3 hours. The precipitate represents the $81.2 \%$ of the mass of the starting material (25.3 mg). The mixture was centrifuged, the solid washed twice with THF (1 mL) and partially dissolved in pyridine. Upon slow diffusion of hexane into the pyridine solution of the reaction mixture a powder formed together with a few single crystals of a minor product suitable for X-ray diffraction, of $\left[\left\{\mathrm{K}(\mathrm{THF})_{3}\right\} \mathrm{U}_{2}(\mu-\mathrm{O})\left(\mathrm{CO}_{2}\right.\right.$-CO-cyclotrensal)(U(trensal))], complex 4. The formation of the crystals was not reproducible.
X-ray Crystallography The diffraction data (except compound 4) were collected at $100 \mathrm{~K}$ using Mo $K_{\alpha}$ radiation on a Bruker APEX II CCD diffractometer equipped with a kappa geometry goniometer. The dataset were reduced by EvalCCD ${ }^{21}$ and then corrected for absorption..$^{22}$ The data for crystal structure 4 was collected at $140 \mathrm{~K}$ using $\mathrm{Cu} K_{\alpha}$ radiation on a Rigaku SuperNova dual system in combination with Atlas type CCD detector. The data reduction and correction were carried out by CrysAlis ${ }^{\text {Pro. }}{ }^{23}$

The solutions and refinements were performed by SHELXT ${ }^{24}$ and SHELXL, ${ }^{25}$ respectively. The crystal structures were refined using full-matrix least-squares based on $F^{2}$ with all non hydrogen atoms anisotropically defined. Hydrogen atoms were placed in calculated positions by means of the "riding" model. Additional electron density (due to disordered solvent molecules) found in the difference Fourier map of compound 1a, 2 and $\mathbf{4}$ was treated by the SQUEEZE algorithm of PLATON. ${ }^{26}$ Similarity and rigid bond restraints (SADI, SIMU and RIGU cards) were employed during the last stages of refinement of $\mathbf{2}$ and $\mathbf{3}$, because of the disorder displayed by the two structures. In the case of compound 1a, the anisotropic behaviour of light atoms was rather unstable; hence adapted restraints were applied to carbons and nitrogens (SIMU and RIGU cards). The crystal structure of $\mathbf{4}$ displayed unusual atomic parameters for the THF molecules and some restraints were used in order to get acceptable distances, angles and adp's (SIMU, DFIX cards). Constraints were applied to the adp's of 013 and 015 (EADP card).

\section{RESULTS AND DISCUSSION}

Synthesis of [ $\mathbf{U}_{2}$ (bis-Rtrensal)] complexes. The reaction between $\mathrm{K}_{3}{ }^{\mathrm{t}} \mathrm{Bu}$-trensal and $\mathrm{UI}_{3}(\mathrm{THF})_{4}$ led to the dinuclear uranium(IV) [U $\mathrm{U}_{2}$ (bis-tBu-trensal)], complex 1a (Scheme 3). Two U(III) cations provide one electron each to give a dinuclear uranium(IV) complex in which two imino groups of two tBu-trensal ligands are coupled.

The molecular structure of 1a (Figure 1) shows a dinuclear uranium(IV) complex with an inversion center at half length of the $\mathrm{C}-\mathrm{C}$ bond connecting the two tButrensal units in the bis-tBu-trensal ligand.

Each uranium center is heptacoordinated in a distorted capped trigonal prismatic environment by two imino nitrogen, one amino nitrogen $(\mathrm{U}-\mathrm{N} 2=2.753(9) \AA)$, one amido nitrogen and three phenoxide oxygen atoms (average $\mathrm{U}-\mathrm{O}=2.22(6) \AA$ ) of the bis-tBu-trensal ligand. The C- $\mathrm{N}_{\text {amido }}$ bond distances ( $\mathrm{C}-\mathrm{N}_{\mathrm{am}}=1.493(14) \AA$ ) of the ligand backbone are much longer than the $\mathrm{C}-\mathrm{N}_{\text {imino }}$ distance in complex $\mathbf{2}$ (see below) and are in agreement with the presence of two amido groups. The value of the $U$ $\mathrm{N}_{\text {amido }}$ distance in 1a (U-N3= 2.312(9) $\AA$ ) falls in the range of values reported for U(IV)-amido compounds ${ }^{27}$ and is significantly shorter that the value found for the $\mathrm{U}-\mathrm{N}_{\mathrm{imin}}$ distances in 1a (average $\mathrm{U}-\mathrm{N}=2.56(2) \AA$ ). These distances compare well with the values reported for $\mathrm{Na}_{2}\left[\mathrm{U}^{\mathrm{IV}}\right.$ (bissalophen)] (U-Nam (2.387(8) $\AA$ ) and U-Nim (2.624(7) $\AA$ )..$^{2 \mathrm{e}}$ The two uranium centers are located in the two pockets of the dinucleating ligand with a U-U distance of 7.311(2) A. The structural parameters of the complex clearly show that a reduction has occurred on the imino groups of the ligands resulting in the formation of a U(IV) complex of the reduced ligand rather than the formation of a U(III) complex of the ${ }^{\mathrm{B} u}$-trensal. Notably, the two electron 
reduction of the ligand results in the formation of the $\mathrm{C}-\mathrm{C}$ bond (C20-C20 =1.59(2) $\AA$ ), by intermolecular reductive coupling of the original imino groups. The value of the C$\mathrm{C}$ bond distance falls in the range of the intermolecular and intramolecular C-C bonds of $\mathrm{Na}_{2}$ [U(bis-salophen)]

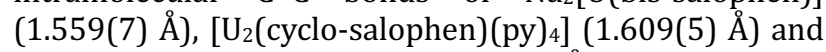

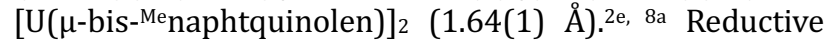
coupling mediated by low valent uranium has also been previously reported for carbonyl compounds, ${ }^{28}$ heterocycles, ${ }^{2 \mathrm{c}} \mathrm{CO}^{29}$ and $\mathrm{CS}_{2 .}{ }^{30}$

The proton NMR of the reaction mixture leading to the isolation of crystals of 1 a shows the presence of the signals assigned to the complex, but also signals of additional species which prevented the isolation of the complex in analytically pure form.

In contrast, ${ }^{1} \mathrm{H}$ NMR studies (Figure 2 ) show that the reaction of $\mathrm{K}_{3}$ trensal with $\mathrm{UI}_{3}(\mathrm{THF})_{4}$ leads to the formation of a single species showing 27 narrow signals assigned to the symmetric dinuclear uranium(IV) [U $\mathrm{U}_{2}$ (bistrensal)], complex 1 (Scheme 1). ESI-MS analysis of complex 1 (see SI) revealed the presence of the dinuclear complex as the only species $(1387.5 \mathrm{~m} / \mathrm{z})$. Any attempt to obtain X-ray quality crystals of $\mathbf{1}$ were unsuccessful but the complex was isolated in $66.6 \%$ yield.

\section{Scheme 3. Synthesis of [ $\mathrm{U}_{2}$ (bis-Rtrensal)], 1.}

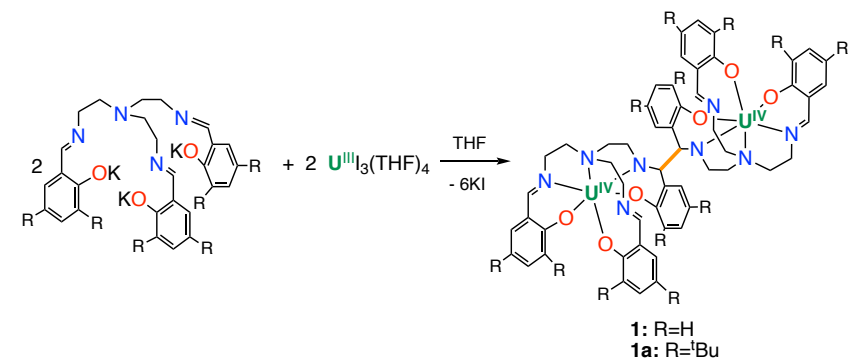

Figure 1. Molecular structure of complex 1a. Hydrogen atoms and methyl groups omitted for clarity. Color cod: uranium (green), nitrogen (blue), oxygen(red), carbon (grey), C-C bond between imine (yellow).

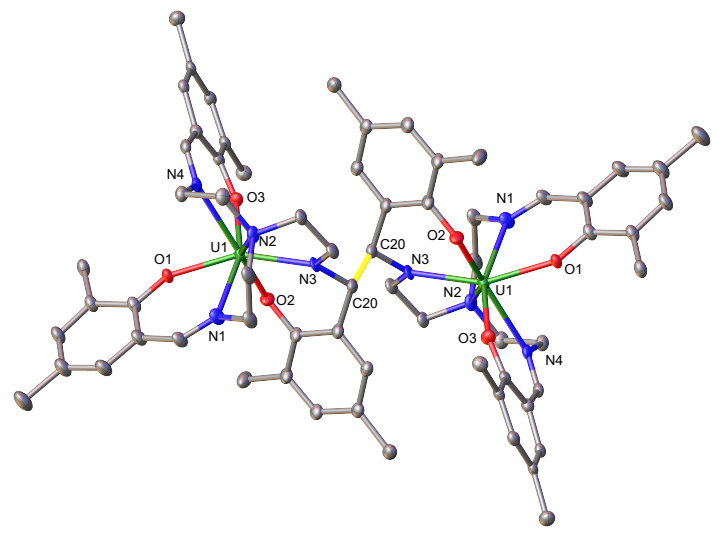

Figure 2. ${ }^{1} \mathrm{H}$ NMR spectrum of complex 1.

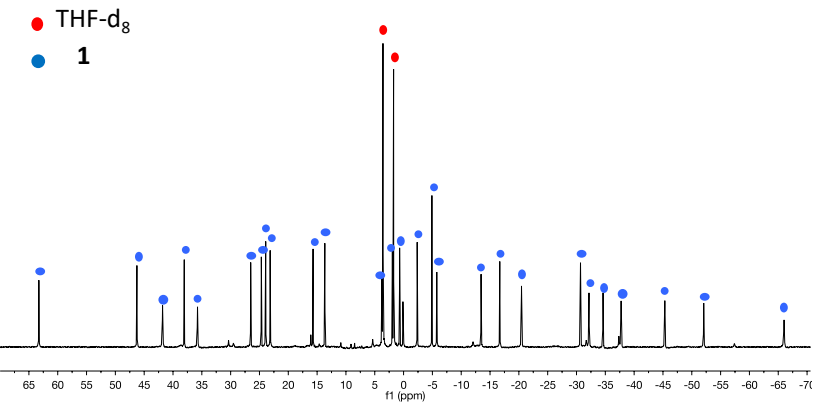

Reactivity of [ $\mathbf{U}_{2}$ (bis-trensal)]. The two electrons stored in the $\mathrm{C}-\mathrm{C}$ bond of the bis-trensal ligand in complex $\mathbf{1}$ are readily available for the reduction of strongly oxidizing substrates, similarly to what reported for $\mathrm{Na}_{2}[\mathrm{U}$ (bissalophen $)]$ and $[\mathrm{U}(\mu \text {-bis-Menaphtquinolen })]_{2}$ complexes. $^{8 \mathrm{a}}$ The reaction of $\mathbf{1}$ with two equiv. of AgOTf led to the immediate oxidation of complex $\mathbf{1}$ with immediate cleavage of the $\mathrm{C}-\mathrm{C}$ bond in the bis-trensal ligand and restoration of the imino groups of the trensal ligand. Thus, the two electrons stored on the bis-trensal ligand react with the $\mathrm{Ag}^{+}$ions to produce $\mathrm{Ag}$ and the monocationic U(IV) complex of the trensal ligand [U(trensal)]OTf, 2 (Scheme 4).

\section{Scheme 4. Reaction of 1 with AgOTf}

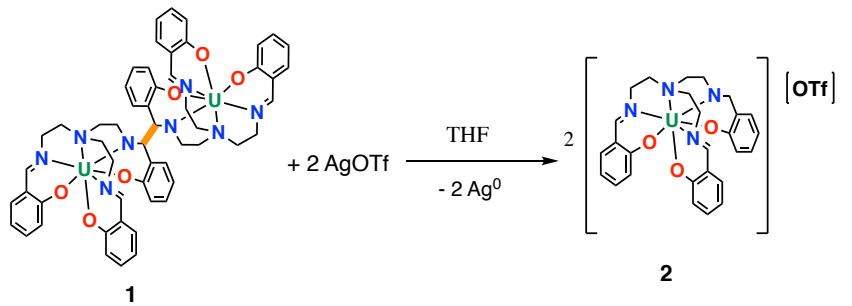

The X-ray crystal structure of 2 (Figure 3) shows the presence of a mononuclear U(IV) complex with the triflate anion in the outer coordination sphere. The U(IV) center in $\mathbf{2}$ is heptacoordinated, with a distorted capped octahedral geometry, by the three imino nitrogen $(\mathrm{U}-\mathrm{N} 1=$ 2.513(8) $\AA)$, the amino nitrogen $(\mathrm{U}-\mathrm{N} 2=2.782(13) \AA$ ) and the three phenoxide oxygen atoms (average $\mathrm{U}-\mathrm{O}=$ $2.162(7) \AA$ ) of a trensal ligand. The values of the U-N and $\mathrm{U}-\mathrm{O}$ bond distances fall in the range of those found in the previously reported eight-coordinated U(IV)complex $\left[\mathrm{U}\left(\right.\right.$ trensal)(py)]I $\left(\mathrm{U}-\mathrm{N}_{\mathrm{im}}=2.54(1) \AA ̊ \mathrm{avg}, \mathrm{U}-\mathrm{N}_{\mathrm{am}}=2.855(5)\right.$ $\AA ̊$ and $\mathrm{U}-\mathrm{O}=2.192(6) \AA ̊) .11 \mathrm{a}$

Figure 3. Molecular structure of complex 2. Hydrogen atoms and triflate anion omitted for clarity. Color code: uranium (green), nitrogen (blue), oxygen(red), carbon (grey).

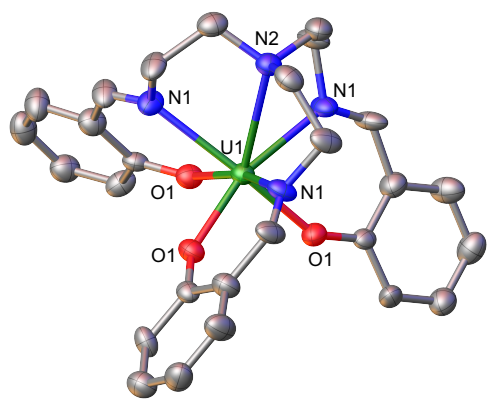


The oxidation and cleavage of $\mathbf{1}$ by addition of AgOTf, led us to investigate the reactivity with $\mathrm{CO}_{2}$. In spite of the fact that no reactivity with $\mathrm{CO}_{2}$ was reported for the $\mathrm{Na}_{2}$ [U(bissalophen $)]$ and $[U(\mu \text {-bis-Menaphtquinolen })]_{2}$ complexes, the addition of excess $\mathrm{CO}_{2}(1 \mathrm{~atm})$ to a THF solution of $\mathbf{1}$ resulted in the slow disappearance of the proton NMR signals of 1 and in the appearance of a new set of 54 signals together with the formation of a pale orange precipitate within 6 days.

\section{Scheme 5. Reactivity of 1 with $\mathrm{CO}_{2}$.}

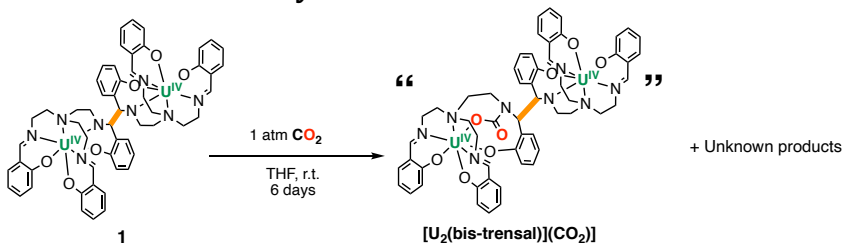

All the attempts to crystallize the products of the reaction were not successful. The reaction of $\mathbf{1}$ with $\mathrm{CO}_{2}$ most probably involves $\mathrm{CO}_{2}$ insertion into the $\mathrm{U}-\mathrm{N}_{\text {amide }}$ bond. This hypothesis is corroborated by the lack of reactivity with $\mathrm{CS}_{2}$, less prone to insertion reactions into $\mathrm{U}-\mathrm{N}$ bonds. The possibility of insertion of $\mathrm{CO}_{2}$ into the $\mathrm{U}-\mathrm{O}$ bond cannot be completely ruled out but the isolation of crystals of 4 (see below) is consistent with the insertion occurring in the $\mathrm{U}-\mathrm{N}_{\text {amide }}$ bond. Moreover, $\mathrm{CO}_{2}$ reduction products such as oxalate or carbonate were not observed in the ${ }^{13} \mathrm{C}\left\{{ }^{1} \mathrm{H}\right\}$ NMR spectrum of the crude mixture, in THF or in the spectrum of the reaction mixture after quenching with basic $\mathrm{D}_{2} \mathrm{O}(\mathrm{pD}=12)$. In contrast the ${ }^{13} \mathrm{C}\left\{{ }^{1} \mathrm{H}\right\}$ NMR spectrum in THF of the soluble fraction of the reaction mixture after reaction of ${ }^{13} \mathrm{CO}_{2}$ with $\mathbf{1}$ shows only one signal at a chemical shift of 202 ppm (Figure S7) and after quenching with basic $\mathrm{D}_{2} \mathrm{O}(\mathrm{pD}=12)$ a signal at $162.5 \mathrm{ppm}$ compatible with the presence of a carbamate (Figure S10).

The mass spectrum of the solution shows a peak at 1431.6 $\mathrm{m} / \mathrm{z}$, consistent with the presence of the $\left[\mathrm{U}_{2}\right.$ (bistrensalCO $\mathrm{C}_{2}$ )] species. The insertion of $\mathrm{CO}_{2}$ into $\mathrm{U}-\mathrm{N}_{\text {amide }}$ bonds has been previously reported for U(III) and U(IV) complexes ${ }^{4 g}, 31$ but was not observed for the amido ligands resulting from the reduction of imino groups in uranium Schiff Base complexes. The higher reactivity of $\mathbf{1}$ with respect to the $\mathrm{CO}_{2}$ insertion reaction compared to the $\mathrm{Na}_{2}[\mathrm{U}$ (bis-salophen $\left.)\right]$ and $[\mathrm{U}(\mu \text {-bis-Menaphtquinolen })]_{2}$ complexes is probably the result of the higher flexibility of the tripodal trensal framework, although the presence of a more polarized $\mathrm{C}-\mathrm{N}_{\text {amido }}$ bond and of a more nucleophilic nitrogen atom cannot be ruled out.

The orange solid formed (accounting for the $60 \%$ of the mass of the $\mathbf{1}$ compound) upon addition of ${ }^{13} \mathrm{CO}_{2}$ to $\mathbf{1}$ is insoluble in THF but can be solubilized in pyridine.

The ${ }^{13} \mathrm{C}\left\{{ }^{1} \mathrm{H}\right\}$ NMR spectrum of the resulting pyridine solution after removing all volatiles and quenching the solution with basic $\mathrm{D}_{2} \mathrm{O}(\mathrm{pD}=12)$ did not show any $\mathrm{CO}_{2}$ reduction products but only the presence of three carbamate signals in the range 162-164 ppm (Figure S11) suggesting that multiple insertion products may form in the reaction.

Synthesis of [ $\left[\mathbf{K}(\mathrm{THF})_{3}\right\}_{2} \mathbf{U}_{2}$ (cyclo-trensal)], 3-THF. The reduction of complex 1 with 2 equivalents of $\mathrm{KC}_{8}$ led to the reductive coupling of two imino groups from two different trensal units in the bis-trensal ligand yielding the dinuclear macrocyclic complex $\left[\left\{\mathrm{K}(\mathrm{THF})_{3}\right\}_{2} \mathrm{U}_{2}\right.$ (cyclotrensal)], 3-THF (Scheme 6). The ${ }^{1} \mathrm{H}$ NMR of the reaction mixture did not show any signals probably due to the presence of fluxional solution species. The ${ }^{1} \mathrm{H}$ NMR spectrum of 3 remains silent at low temperature $\left(-40^{\circ} \mathrm{C}\right)$ and in pyr- $\mathrm{d}_{5}$. Single crystals suitable for X-ray diffraction of $\left[\left\{\mathrm{K}(\mathrm{Py})_{3}\right\}_{2} \mathrm{U}_{2}\right.$ (cyclo-trensal)], 3-py, were obtained by slow diffusion of hexane into a pyridine solution of 3-THF. A crystallographic inversion center is located between the two uranium centers and relates the two halfs of the macrocyclic complex.

\section{Scheme 6. Reduction of 1 with 2 equiv. KC8}

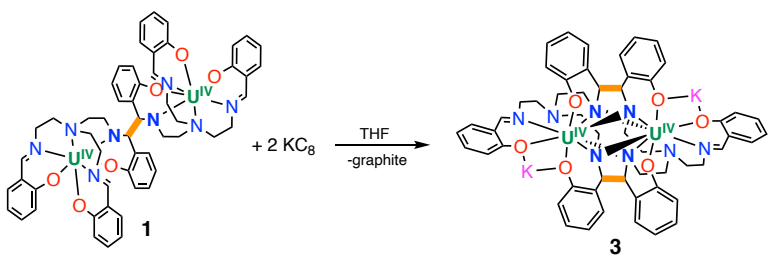

The structural parameters of 3-py (Figure 4) point unambiguously to the presence of a U(IV) dimer complexed by the dodecadentate decaanionic amidophenolate macrocyclic ligand cyclo-trensal formed through two reductive $\mathrm{C}-\mathrm{C}$ coupling reactions between two trensal ligands. The resulting dinucleating cyclotrensal ligand in 3-py holds the two uranium atoms in close proximity, at a shorter U-U distance of 3.439(2) $\AA$ compared to the previously reported distance in $\left[\mathrm{U}_{2}\right.$ (cyclosalophen)(py) 4 ] complex (U-U = 3.54(1) Å).2e

Each uranium centre in 3-py is nonacoordinated in a distorted tricapped trigonal prismatic environment by four bridging amido nitrogens (N3 and N1) (mean U-N= $2.54(3) \AA$ ), one imino nitrogen (U-N4 = 2.581(8) $\AA$ ), one amino nitrogen $(\mathrm{U}-\mathrm{N} 2=2.722(8) \AA$ ) and three phenoxide oxygen atoms (mean $\mathrm{U}-\mathrm{O}=2.34(3) \AA)$. Two of the phenoxide oxygen atoms (02) coordinate a $\mathrm{K}^{+}$cation, together with three molecules of pyridine.

The C-N3 and C-N1 bond distances (mean C-N $\mathrm{N}_{\mathrm{am}}=1.49$ (2) $\AA$ ) of the ligand backbone are much longer than the $\mathrm{C}-\mathrm{N}$ bond distances found in complex $\mathbf{2}$ and are in agreement with the presence of four amido groups. Similarly, the values of the $\mathrm{U}-\mathrm{N}_{\mathrm{am}}$ bond distances in 3-py (mean value $\mathrm{U}-$ $\mathrm{N}_{\mathrm{am}}=2.54(3) \AA$ ) are significantly shorter than the $\mathrm{U}-\mathrm{N}_{\mathrm{im}}$ distances in 3-py $\left(\mathrm{U}-\mathrm{N}_{\mathrm{im}}=2.581(8) \AA\right.$ ) and in 2. These values compare well with those reported for the macrocyclic amidophenolate complex [ $\mathrm{U}_{2}($ cyclosalophen)(py) 4 ] (avg value $\mathrm{C}-\mathrm{N}=1.473(4) \AA \AA$, $\mathrm{U}-\mathrm{N}=2.39$ $2.60 \AA)^{2 e}$

The value of the C-C bond distances (1.553(13) $\AA$ ) fall in the range of those found for the intermolecular and intramolecular $\mathrm{C}-\mathrm{C}$ bonds in $\mathrm{Na}_{2}$ [U(bis-salophen)] (1.559(7) Å), [U $\mathrm{U}_{2}$ (cyclo-salophen)(py) 4 ] (1.609(5) $\AA$ ) and $\left[\mathrm{U}(\mu \text {-bis-Menaphtquinolen) }]_{2} \text { (1.64(1) } \AA\right)^{2 \mathrm{e}, 8 \mathrm{a}}$

Figure 4. Molecular structure of complex 3-py. Hydrogen atoms and pyridine molecules are omitted for clarity. Color cod: uranium (green), nitrogen (blue), oxygen(red), carbon (grey), C-C bond between imine (yellow) 


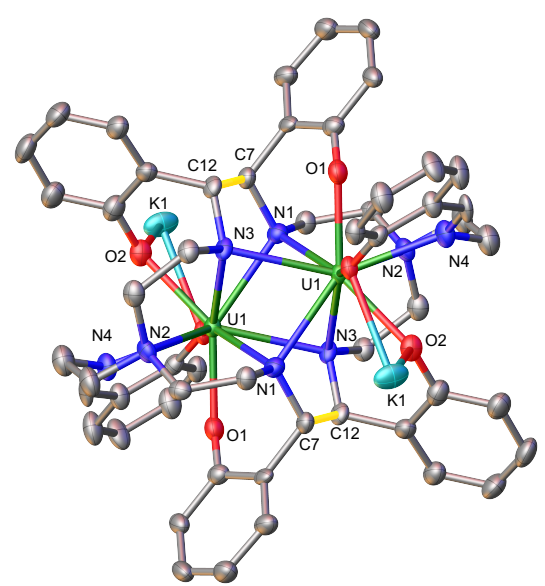

Reactivity of $\left[\left\{\mathrm{K}(\mathrm{THF})_{3}\right\}_{2} \mathrm{U}_{2}\right.$ (cyclo-trensal)], 3-THF. In previous studies we showed that the electrons stored in the two $\mathrm{C}-\mathrm{C}$ bonds of the cyclo-salophen ligand in $\left[\mathrm{U}_{2}\right.$ (cyclo-salophen)(py) 4$]$ can become available to strong oxidizing agents such as AgOTf and phenanthrenequinone leading to cleavage of the $\mathrm{C}-\mathrm{C}$ bonds and formation of the original salophen Schiff base ligand. However, complex $\left.\left[\mathrm{U}_{2} \text { (cyclo-salophen)(py) }\right)_{4}\right]$ did not react with small molecules such as $\mathrm{CS}_{2}$ and $\mathrm{CO}_{2}$.

${ }^{1} \mathrm{H}$ NMR studies showed that complex $\mathbf{3}$ also reacts rapidly with 2 equiv. or 4 equiv. of AgOTf resulting in the cleavage of one or the two $\mathrm{C}-\mathrm{C}$ bonds and formation of $\left[\mathrm{U}_{2}\right.$ (bistrensal)], $\mathbf{1}$ and [U(trensal)]OTf, $\mathbf{2}$ complexes, respectively.

Remarkably complex 3 also reacts with excess ${ }^{13} \mathrm{CS}_{2}$ leading to cleavage of one $\mathrm{C}-\mathrm{C}$ bond in the cyclotrensal ligand, formation of the bis-trensal complex $\mathbf{1}$ and release of ${ }^{13} \mathrm{CS}_{2}$ reduction products. From the ${ }^{13} \mathrm{C}\left\{{ }^{1} \mathrm{H}\right\}$ NMR of the reaction mixture in DMSO- $\mathrm{d}_{6}$ the presence of $\mathrm{CS}_{3}{ }^{2-}$ and $\mathrm{C}_{2} \mathrm{~S}_{4}{ }^{2-}$ and $\mathrm{C}_{3} \mathrm{~S}_{5}{ }^{2-}$ (from $\mathrm{C}_{2} \mathrm{~S}_{4}{ }^{2-a n d} \mathrm{CS}$ ) was identified. ${ }^{20}$

\section{Scheme 7. Reaction of 3 with ${ }^{13} \mathrm{CS}_{2}$}

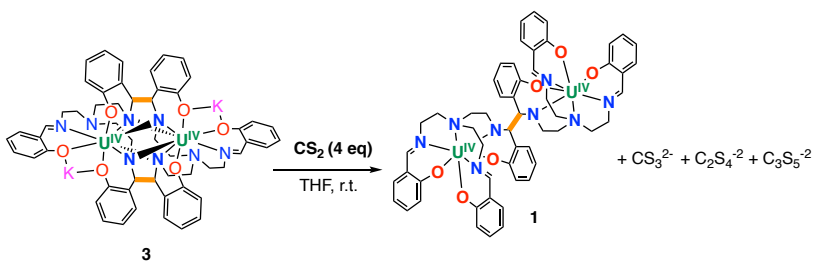

Complex 3 also reacted with two equivalents of $\mathrm{CO}_{2}$ and the ${ }^{1} \mathrm{H}$ NMR spectrum of the reaction mixture taken immediately after the addition (Figures S23) showed only the presence of the signals assigned to the THF soluble complex 1 (Scheme 8).

The outcome of the reaction was also investigated by quantitative ${ }^{13} \mathrm{C}\left\{{ }^{1} \mathrm{H}\right\}$ NMR in basic $\mathrm{D}_{2} \mathrm{O}(\mathrm{pD}=12)$. After quenching the reaction mixture in basic $\mathrm{D}_{2} \mathrm{O}(\mathrm{pD}=12)$ quantitative ${ }^{13} \mathrm{C}\left\{{ }^{1} \mathrm{H}\right\}$ NMR showed the presence of ${ }^{13} \mathrm{CO}_{3}{ }^{2-}$ in $80 \%$ yield (calculated with respect to the value expected if only two molecules of $\mathrm{CO}_{2}$ react with $\mathbf{3}$ as shown in Scheme 8).

The presence of carbonate indicated that the electrons stored in the two $\mathrm{C}-\mathrm{C}$ bonds in complex $\mathbf{3}$ can become available for the reduction of $\mathrm{CO}_{2}$. Notably, formation of $\mathrm{CO}_{3}{ }^{2-}$ is the result of the reductive disproportionation of $\mathrm{CO}_{2}$ by the highly reducing complex 3 . In contrast, no formation of carbonate was observed after reaction of complex 1 with $\mathrm{CO}_{2}$.

The reductive disproportionation of carbon dioxide to afford carbonate and $\mathrm{CO}$ was reported for U(III) complexes but never reported for U(IV) compounds. ${ }^{4 a}, 32$

The addition of higher amounts of $\mathrm{CO}_{2}$ (4 equiv., see supporting information) did not lead to an increase in carbonate (78.2\%) suggesting that only two out of the four electrons stored in the two bonds in $\mathbf{3}$ effects the reductive disproportionation of $\mathrm{CO}_{2}$ with concomitant formation of 1. The addition of 4 equiv. of $\mathrm{CO}_{2}$ however also leads to formation of insertion products detected by ${ }^{1} \mathrm{H}$ NMR of the reaction mixture recorded in THF- $\mathrm{d}_{8}$ after several days.

\section{Scheme 8. Redox reaction of 3 with two equivalents of} $\mathrm{CO}_{2}$

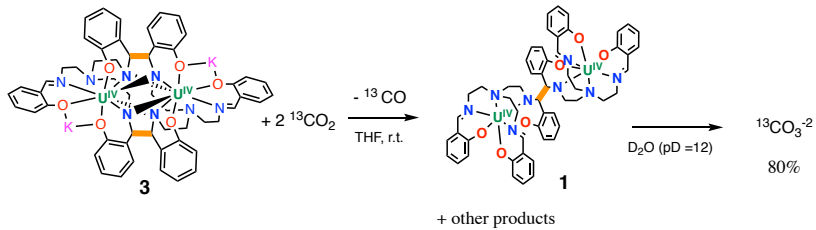

When complex 3 is exposed to a large excess of $\mathrm{CO}_{2}(100$ equiv or $1 \mathrm{~atm}$ ) in THF the immediate formation of a solid is observed. The ${ }^{1} \mathrm{H}$ NMR of the solid dissolved in DMSO- $\mathrm{d}_{6}$ showed the presence of multiple species. The ${ }^{13} \mathrm{C}\left\{{ }^{1} \mathrm{H}\right\} \mathrm{NMR}$ of the reaction mixture (after addition of 100 equiv. ${ }^{13} \mathrm{CO}_{2}$ ) quenched in basic $\mathrm{D}_{2} \mathrm{O}(\mathrm{pD}=12)$ showed the presence of ${ }^{13} \mathrm{CO}_{3}{ }^{2-}$ in $90 \%$ yield (calculated with respect to the value expected if only two molecules of $\mathrm{CO}_{2}$ react with 3 as shown in Scheme 8). The ${ }^{13} \mathrm{C}\left\{{ }^{1} \mathrm{H}\right\}$ NMR also shows also the presence of an additional signal assigned to insertion products (162.5 ppm).

Scheme 9. Structure of complex 4 , a minor product isolated from the reaction of 3 with excess $\mathrm{CO}_{2}$

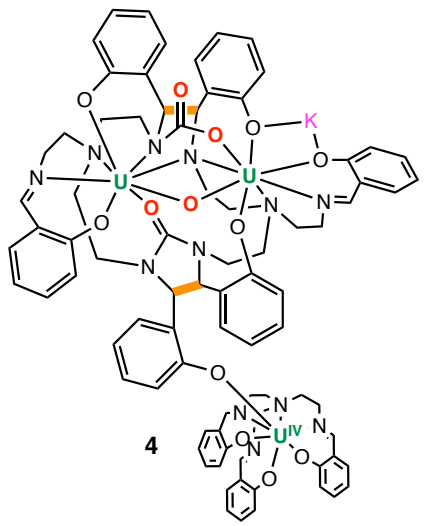

Recrystallization of the solid isolated from pyridine, after addition of $1 \mathrm{~atm} \mathrm{CO}_{2}$ to 3 , by slow diffusion of hexane in the resulting pyridine solution afforded after long time a few single crystals suitable for $\mathrm{X}$ ray diffraction. The 
formation of the crystals was not reproducible but allowed to identify a notable product of reactivity, complex 4, $\left[\left\{\mathrm{K}(\mathrm{THF})_{3}\right\} \mathrm{U}_{2}(\mu-\mathrm{O})\left(\mathrm{CO}_{2}\right.\right.$-CO-cyclo-trensal $)(\mathrm{U}($ trensal $\left.))\right]$ (Scheme 9).

The molecular structure of 4 (Figure 5) shows a trinuclear U(IV) complex resulting from three different types of reactivity. The insertion of a $\mathrm{CO}_{2}$ molecule into one out of the four $\mathrm{U}-\mathrm{N}_{\text {amido }}$ bonds of $\mathbf{3}$ is observed and provides additional evidence for the formation of a $\left[\mathrm{U}_{2}\right.$ (bistrensalCO ${ }_{2}$ )] species in the reaction of 1 with $\mathrm{CO}_{2}$. A second molecule of $\mathrm{CO}_{2}$ is cleaved leading to a bridging oxide and $\mathrm{CO}$ addition to two $\mathrm{U}-\mathrm{N}_{\text {amido }}$ bonds followed by the formation of a cycloimidazolidinone five membered heterocycle. The $\mathrm{CO}_{2}$ cleavage is probably promoted by the cooperative interaction of two uranium centers and of the nucleophilic amido groups of the cyclo-trensal ligand (Figure 5, b).

Finally, a third process must have occurred in the reaction with $\mathrm{CO}_{2}$ since in the molecular structure, a [U(trensal)] ${ }^{+}$ cation is found, suggesting that two $\mathrm{C}-\mathrm{C}$ bonds of the cyclotrensal ligand have been cleaved to restore the original imino groups, through transfer of four electrons to the $\mathrm{CO}_{2}$ substrate affording carbonate and $\mathrm{CO}$. The fact that free $\mathrm{CO}$ is not observed by ${ }^{13} \mathrm{C}\left\{{ }^{1} \mathrm{H}\right\}$ NMR spectroscopy can be explained by its insertion into the $\mathrm{U}-\mathrm{N}_{\text {amido }}$ bonds. Insertion of $\mathrm{CO}$ into $\mathrm{U}-\mathrm{N}_{\text {amido }}$ bonds is reported in literature. ${ }^{33}$

The molecular structure of $\mathbf{4}$ shows a trimeric U(IV) complex. Two uranium centres, $\mathrm{U} 1$ and $\mathrm{U} 2$, are bound by the $\mathrm{CO}_{2}$-CO-cyclo-trensal ligand resulting from the insertion of one $\mathrm{CO}$ and one $\mathrm{CO}_{2}$ molecule in the cyclotrensal framework (Figure 5a). The U1 and U2 centers are held together in close proximity at a distance of 3.7266(7) $\AA$, slightly longer than the U-U distance found in 3 . The two centres are bridged by a $\mu$-oxo ligand, the $\mu$ amido nitrogen and $\mu-\mathrm{k}_{2}(\mathrm{kO}: \mathrm{kN})$ carbamate from the $\mathrm{CO}_{2}-$ $\mathrm{CO}$-cyclo-trensal ligand. $\mathrm{U} 1$ is octacoordinated and its coordination sphere is completed by one amino nitrogen (U1-N3 = 2.694(14) $\AA$ ), one imino nitrogen (U1-N2= 2.648(14) $\AA$ ), and three phenoxide oxygens (mean U1-0 = $2.31(3) \AA ̊)$. The carbamate moiety is formed upon insertion of a $\mathrm{CO}_{2}$ molecule in a $\mathrm{U}-\mathrm{N}_{\text {amido }}$ bond. $\mathrm{U} 2$ is also octacoordinated and its coordination sphere is completed by one amino nitrogen (U1-N6 = 2.698(14) A), one imino nitrogen (U1-N7= 2.570(12) $\AA$ ), one amido nitrogen (U2N8 $=2.649(14) \AA$ ), two phenoxide oxygen (mean U-O = 2.297(7) $\AA$ ), and one oxygen from the cycloimidazolidinone fragment in the $\mathrm{CO}_{2}-\mathrm{CO}-$ cyclotrensal ligand.

The structural parameters of the five member heterocycle formed from the addition of $\mathrm{CO}$ to the cyclo-trensal ligand $(\mathrm{C} 30-05$ distance $=1.302(19) \AA, \quad \mathrm{C} 30-\mathrm{N} 5$ distance $=$ $1.32(2) \AA$ and C30-N4 distance $=1.36(2) \AA$ ) are similar to those reported values for free cyclo-imidazolidinones. ${ }^{34}$

A $\mathrm{K}^{+}$cation is hexacoordinated by the two phenoxide coordinated to $\mathrm{U} 1$, an oxygen from the inserted $\mathrm{CO}_{2}$ molecule and 3 THF oxygens. One appended phenoxide ligand (013) of the $\mathrm{CO}_{2}$-CO-cyclo-trensal ligand, binds the $\mathrm{U} 3$ atom of a [U(trensal) $]^{+}$moiety.

The unusual structure of $\mathbf{4}$ consisting of two different components, the macrocyclic dinuclear anionic complex $\left[\mathrm{K}(\mathrm{THF})_{3} \mathrm{U}_{2}(\mu-\mathrm{O})\left(\mathrm{CO}_{2} \text {-CO-cyclo-trensal }\right)\right]^{-}$and the cationic $[\mathrm{U}(\text { trensal })]^{+}$complex is probably at the origin of the lack of reproducibility in crystal isolation. However, the structure of $\mathbf{4}$ gives a clear indication of the multiple processes occurring when complex $\mathbf{3}$ is reacted with a large excess of $\mathrm{CO}_{2}$.

Figure 5 a) structure of 4 after removing the $\left[\mathrm{U}(\text { trensal) }]^{+}\right.$arm b) Detail of the structure showing the inserted and cleaved $\mathrm{CO}_{2}$ molecules. Hydrogen atoms and methyl groups were omitted for clarity. Color code: uranium (green), nitrogen (blue), oxygen (red), carbon (grey), C-C bond between imine (yellow).

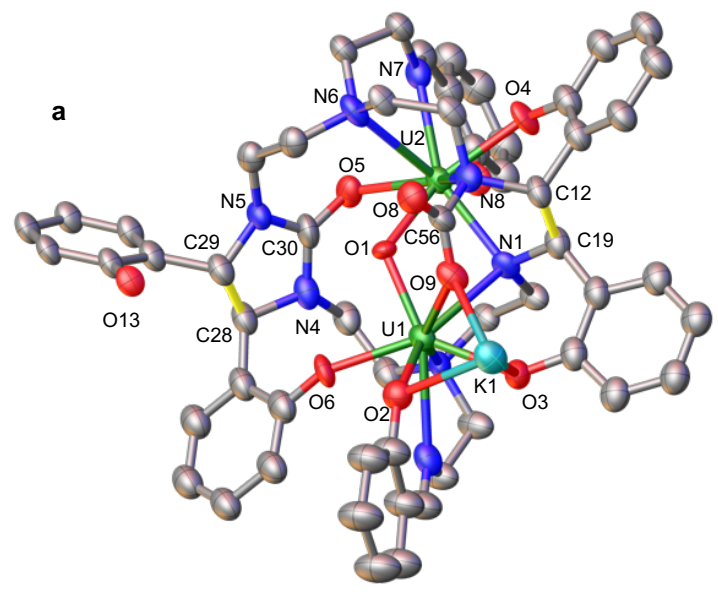

b

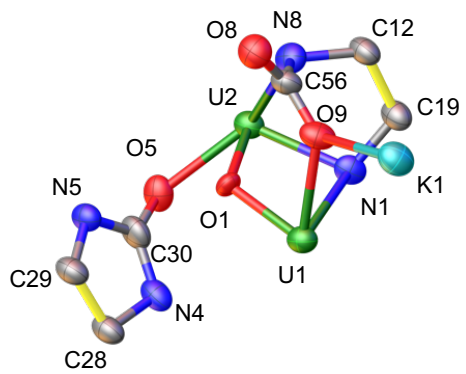

\section{Electrochemistry.}

In contrast with what observed previously with the $\left.\left[\mathrm{U}_{2} \text { (cyclo-salophen)(py) }\right)_{4}\right]$ the electrons stored on the trensal ligand via the formation of $\mathrm{C}-\mathrm{C}$ bonds can become available for the reduction of $\mathrm{CO}_{2}$ to carbonate. In order to understand the origins of the higher reactivity of the $\mathrm{C}-\mathrm{C}$ bond in the $\left[\left\{\mathrm{K}(\mathrm{THF})_{3}\right\}_{2} \mathrm{U}_{2}\right.$ (cyclo-trensal)], 3-THF complex we performed electrochemistry studies of the complexes 1 and 2.

Cyclic voltammetry data were measured for complexes $\mathbf{1}$ and 2 in $\sim 0.1 \mathrm{M}$ pyridine solution of $\left[\mathrm{Bu}_{4} \mathrm{~N}\right]\left[\mathrm{PF}_{6}\right]$ and are presented in Figure 6. All redox potentials are referenced against the $\left[\left(\mathrm{C}_{5} \mathrm{H}_{5}\right)_{2} \mathrm{Fe}\right]^{+/ 0}$ redox couple. The voltammogram of complex $\mathbf{1}$ shows in the first scan only one distinct irreversible reduction event at $\mathrm{E}_{\mathrm{pc}}=-2.53 \mathrm{~V}$ associated with two irreversible redox processes at -0.43 
$\mathrm{V}$ and $-0.07 \mathrm{~V}$. The same peak is present in the cyclic voltammogram of 2 measured in the same conditions, at $\mathrm{E}_{\mathrm{pc}}=-2.50$. In the latter a first irreversible reduction event is occurring at $\mathrm{E}_{\mathrm{pc}}=-2.03 \mathrm{~V}$, which is also observed in the second scan of the voltammogram of $\mathbf{1}$ after oxidation. This event is associated with one irreversible oxidation processes occurring at $\mathrm{E}_{\mathrm{pa}}=-1.48 \mathrm{~V}$ which is not observed in the voltammogram of $\mathbf{1}$ when the voltammogram is swept initially from $-0.91 \mathrm{~V}$ towards the positive direction but is always present in the voltammogram of 2 . These data indicate the presence of a system with a limited degree of chemical reversibility as previously observed for the reduction of U(IV) Schiff base complexes leading to the formation of $\mathrm{C}-\mathrm{C}$ bonds after ligand reduction. Since only one irreversible reduction process was observed for complex 1 the redox process at $\mathrm{E}_{\mathrm{pc}}=-2.50$ is assigned to the ligand reduction leading to the formation of complex 3 while the redox event at $\mathrm{E}_{\mathrm{pc}}=-2.03 \mathrm{~V}$ is assigned to the formation of complex $\mathbf{1}$. The assignment of the event at $E_{p c}=-2.50$ to the formation of complex $\mathbf{3}$ was confirmed by the cyclic voltammogram of $\mathbf{3}$ measured after addition of cryptand which did not show any reduction event in the first scan.

The oxidation event at $-1.48 \mathrm{~V}$ is associated to the twoelectron ligand oxidation in $\mathbf{3}$ while the oxidation event at $-0.55 \mathrm{~V}$ is associated to the second successive twoelectrons ligand oxidation leading from 1 to 2 . The irreversibility of the ligand-based processes arises from the fact that the electrochemical reduction and oxidation is followed by a rapid chemical transformation involving the formation or cleavage of the $\mathrm{C}-\mathrm{C}$ bond between two reduced imino groups.

The pseudo-reversible redox event observed in the voltammograms of both $\mathbf{1}$ and $\mathbf{2}$, with $\mathrm{E}_{\mathrm{pa}}=0.37 \mathrm{~V}$ and $\mathrm{E}_{\mathrm{pc}}=$ $0.21 \mathrm{~V}$ is assigned to the $\mathrm{U}(\mathrm{IV}) / \mathrm{U}(\mathrm{V})$ metal centered redox event. This fits with the range of values of redox potentials reported for other $\mathrm{U}(\mathrm{IV}) / \mathrm{U}(\mathrm{V})$ reversible systems in the range $\left(-1.81\right.$ to $0.12 \mathrm{~V} v s$. $\left.\mathrm{Fc}^{+} / \mathrm{Fc}\right){ }^{35}$. The ligand based irreversible oxidation events at $-1.13 \mathrm{~V}$ and -0.13 present in the voltammograms of $\mathbf{1}$ and $\mathbf{2}$ are also observed in the voltammogram of the K3trensal ligand ${ }^{11 a}$ and they could be due to oxidation of the phenol groups.

Electrochemistry studies reported for the U(IV) complex

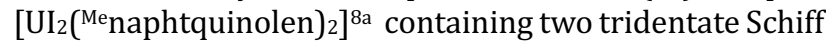
base ligands showed a series of ligand -based and metalbased redox processes. Ligand based reduction was reported to occur in the - 1.49- $-1.70 \mathrm{~V}$ range. Ligand based reduction were found at lower potential in the range -2.17 to $-2.25 \mathrm{~V}$ for the mononuclear U(IV) complexes M[U(bis${ }^{\mathrm{R}}$ salophen)] (M, R =Na, H;K, Me;K, ${ }^{\mathrm{Bu}}$ ) formed from intramolecular reduction of the salophen Schiff base (Scheme 1, bottom). ${ }^{36}$

The ability of complex 3 to reduce $\mathrm{CO}_{2}$ is probably due to its lower reduction potential $\left(\mathrm{E}_{\mathrm{pc}}=-2.50 \mathrm{~V}\right)$ compared to the $\quad\left[\mathrm{UI}_{2}\left({ }^{\mathrm{Men}} \text { naphtquinolen }\right)_{2}\right] \quad \mathrm{M}[\mathrm{U}(\text { bis-Rsalophen })]^{\mathrm{R}}$ complexes and associated to a higher accessibility to the metal center compared to the bis-Menaphtquinolen and bis-salophen complexes.

Figure 6. Room temperature cyclic voltammetry of complexes $4 \mathrm{mM}$ pyridine solutions of $\mathbf{1}$ (blue), $\mathbf{2}$ (orange) and 3 in presence of cryptand (grey) in $\sim 0.1 \mathrm{M}$
$\left[\mathrm{Bu}_{4} \mathrm{~N}\right]\left[\mathrm{PF}_{6}\right]$ at a $100 \mathrm{mV} / \mathrm{sec}$ scan rate versus $\mathrm{Fc}$, using a $\mathrm{Pt}^{0}$ disk as working electrode (arrows indicate scan direction).

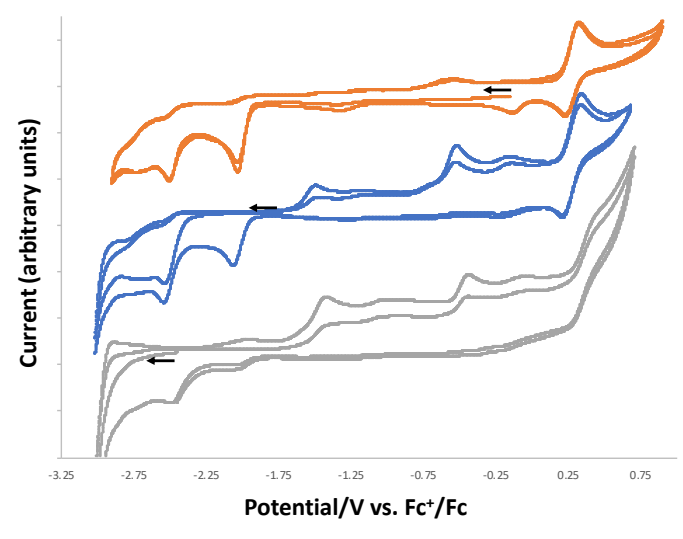

\section{SUMMARY}

Here we have prepared and characterized a new example of dinuclear U(IV) complex (1) resulting from the reductive coupling of the imino groups of the tripodal heptadentate trensal Schiff base by U(III). Complex $\mathbf{1}$ was further reduced to afford the diuranium(IV) complex (3) of the dodecadentate decaanionic amidophenolate macrocyclic ligand cyclo-trensal formed from the reductive $\mathrm{C}-\mathrm{C}$ coupling of two imino groups of two trensal ligands. The electrons stored in the $\mathrm{C}-\mathrm{C}$ bonds in complex $\mathbf{1}$ and $\mathbf{3}$ can become available to strong oxidizing agents such as AgOTf restoring the original imino functions of the trensal ligand. Complex 1 also reacts with $\mathrm{CO}_{2}$ but only insertion reactions into the $\mathrm{U}-\mathrm{N}_{\text {amido }}$ bonds are observed.

In contrast the electrons stored in the $\mathrm{C}-\mathrm{C}$ bonds in the complex $\mathbf{3}$ are also available for the $\mathrm{CO}_{2}$ reduction to carbonate which is the major product for a $3: \mathrm{CO}_{2}$ stoechiometry of 1:2.

Parallel reactions leading to modification of the ligand structure trough insertion reactions into the $\mathrm{U}-\mathrm{N}_{\text {amido }}$ bonds of $\mathrm{CO}_{2}$ and $\mathrm{CO}$ occur in the presence of excess $\mathrm{CO}_{2}$.

The higher reactivity of the reduced complex of cyclotrensal compared to the previously reported U(IV) complexes of reduced Schiff bases is ascribed to more negative redox potential and to the higher flexibility of the trensal scaffold.

Future work will be directed to identify Schiff bases that allow to favor the reduction compared to the insertion reaction.

\section{ASSOCIATED CONTENT}

\section{Supporting Information.}

Selected ${ }^{1} \mathrm{H}$ NMR and ${ }^{13} \mathrm{C}$ NMR spectra, Selected cyclovoltammograms, X-ray crystallographic data and files in CIF format. This material is available free of charge via the Internet at http://pubs.acs.org.

\section{AUTHOR INFORMATION}

\section{Corresponding Author \\ * marinella.mazzanti@epfl.ch}

Author Contributions

All authors have given approval to the final version of the manuscript. 
"The authors declare no competing financial interests."

\section{ACKNOWLEDGMENTS}

We acknowledge support from the Swiss National Science Foundation grant number 200021_ 178793 and the Ecole Polytechnique Fédérale de Lausanne (EPFL). We thank Dr. Euro Solari for carrying out the elemental analyses, Farzaneh Fadaei-Tirani for important contributions to the X-ray single crystal structure analyses.

\section{REFERENCES}

1. (a) Camp, C.; Arnold, J., On the non-innocence of "Nacnacs": ligand-based reactivity in beta-diketiminate supported coordination compounds. J. Chem. Soc.-Dalton Trans. 2016, 45, 14462-14498; (b) Chirik, P. J., Iron- and Cobalt-Catalyzed Alkene Hydrogenation: Catalysis with Both Redox-Active and Strong Field Ligands. Acc. Chem. Res. 2015, 48, 1687-1695; (c) Broere, D. L. J.; Plessius, R.; van der Vlugt, J. I., New avenues for ligand-mediated processes - expanding metal reactivity by the use of redox-active catechol, o-aminophenol and o-phenylenediamine ligands. Chem. Soc. Rev. 2015, 44, 6886-6915; (d) Chirik, P. J.; Wieghardt, K., Radical Ligands Confer Nobility on Base-Metal Catalysts. Science 2010, 327, 794-795; (e) Suarez, A. I. O.; Lyaskovskyy, V.; Reek, J. N. H.; van der Vlugt, J. I.; de Bruin, B., Complexes with NitrogenCentered Radical Ligands: Classification, Spectroscopic Features, Reactivity, and Catalytic Applications. Angew. Chem. Int. Ed. Engl. 2013, 52, 12510-12529; (f) Luca, O. R.; Crabtree, R. H., Redoxactive ligands in catalysis. Chem. Soc. Rev. 2013, 42, 1440-1459; (g) Milsmann, C.; Semproni, S. P.; Chirik, P. J., N-N Bond Cleavage of 1,2-Diarylhydrazines and N-H Bond Formation via H-Atom Transfer in Vanadium Complexes Supported by a Redox-Active Ligand. $J$. Am. Chem. Soc. 2014, 136, 12099-12107; (h) Nguyen, A. I.; Blackmore, K. J.; Carter, S. M.; Zarkesh, R. A.; Heyduk, A. F., Oneand Two-Electron Reactivity of a Tantalum(V) Complex with a Redox-Active Tris(amido) Ligand. J. Am. Chem. Soc. 2009, 131, 3307-3316; (i) Klementyeva, S. V.; Lukoyanov, A. N.; Afonin, M. Y.; Mortel, M.; Smolentsev, A. I.; Abramov, P. A.; Starikova, A. A.; Khusniyarov, M. M.; Konchenko, S. N., Europium and ytterbium complexes with o-iminoquinonato ligands: synthesis, structure, and magnetic behavior. J. Chem. Soc.-Dalton Trans. 2019, 48, 33383348; (j) Galley, S. S.; Pattenaude, S. A.; Higgins, R. F.; Tatebe, C. J.; Stanley, D. A.; Fanwick, P. E.; Zeller, M.; Schelter, E. J.; Bart, S. C., A reduction series of neodymium supported by pyridine(diimine) ligands Dedicated to Professor Geoff Cloke on the occasion of his 65(th) birthday. J. Chem. Soc.-Dalton Trans. 2019, 48, 8021-8025; (k) Fedushkin, I. L.; Lukoyanov, A. N.; Baranov, E. V., Lanthanum Complexes with a Diimine Ligand in Three Different Redox States. Inorg. Chem. 2018, 57, 4301-4309.

2. (a) Carmen, C.; Atienza, H.; Milsmann, C.; Semproni, S. P.; Turner, Z. R.; Chirik, P. J., Reversible Carbon-Carbon Bond Formation Induced by Oxidation and Reduction at a Redox-Active Cobalt Complex. Inorg. Chem. 2013, 52, 5403-5417; (b) Nocton, G.; Lukens, W. W.; Booth, C. H.; Rozenel, S. S.; Medling, S. A.; Maron, L.; Andersen, R. A., Reversible Sigma C-C Bond Formation Between Phenanthroline Ligands Activated by $\left(\mathrm{C}_{5} \mathrm{Me}_{5}\right)(2) \mathrm{Yb} . J$. Am. Chem. Soc. 2014, 136, 8626-8641; (c) Monreal, M. J.; Diaconescu, P. L., Reversible C-C Coupling in a Uranium Biheterocyclic Complex. $J$. Am. Chem. Soc. 2010, 132, 7676-7683; (d) Nocton, G.; Ricard, L., Reversible C-C coupling in phenanthroline complexes of divalent samarium and thulium. Chem. Commun. 2015, 51, 3578-3581; (e) Camp, C.; Mougel, V.; Horeglad, P.; Pecaut, J.; Mazzanti, M., Multielectron Redox Reactions Involving C-C Coupling and Cleavage in Uranium Schiff Base Complexes. J. Am. Chem. Soc. 2010, 132, 17374-17377.

3. (a) Pattenaude, S. A.; Mullane, K. C.; Schelter, E. J.; Ferriere, M. G.; Stein, B. W.; Bone, S. E.; Pacheco, J. S. L.; Kozimor, S. A.; Fanwick, P. E.; Zeller, M.; Bart, S. C., Redox-Active vs RedoxInnocent: A Comparison of Uranium Complexes Containing Diamine Ligands. Inorg. Chem. 2018, 57, 6530-6539; (b) Camp, C.; Toniolo, D.; Andrez, J.; Pecaut, J.; Mazzanti, M., A versatile route to homo- and hetero-bimetallic $5 \mathrm{f}-5 \mathrm{f}$ and $3 \mathrm{~d}-5 \mathrm{f}$ complexes supported by a redox active ligand framework. J. Chem. Soc.-Dalton Trans. 2017, 46, 11145-11148; (c) Anderson, N. H.; Odoh, S. O.; Williams, U. J.; Lewis, A. J.; Wagner, G. L.; Pacheco, J. L.; Kozimor, S. A.; Gagliardi, L.; Schelter, E. J.; Bart, S. C., Investigation of the Electronic Ground States for a Reduced Pyridine(diimine) Uranium Series: Evidence for a Ligand Tetraanion Stabilized by a Uranium Dimer. J. Am. Chem. Soc. 2015, 137, 4690-4700; (d) Kiernicki, J. J.; Newell, B. S.; Matson, E. M.; Anderson, N. H.; Fanwick, P. E.; Shores, M. P.; Bart, S. C., Multielectron C-O Bond Activation Mediated by a Family of Reduced Uranium Complexes. Inorg. Chem. 2014, 53, 3730-3741; (e) Li Manni, G.; Walensky, J. R.; Kraft, S. J.; Forrest, W. P.; Perez, L. M.; Hall, M. B.; Gagliardi, L.; Bart, S. C., Computational Insights into Uranium Complexes Supported by Redox-Active alpha-Diimine Ligands. Inorg. Chem. 2012, 51, 2058-2064; (f) Kraft, S. J.; Fanwick, P. E.; Bart, S. C., Carbon-Carbon Reductive Elimination from Homoleptic Uranium(IV) Alkyls Induced by Redox-Active Ligands. J. Am. Chem. Soc. 2012, 134, 6160-6168; (g) Kraft, S. J.; Williams, U. J.; Daly, S. R.; Schelter, E. J.; Kozimor, S. A.; Boland, K. S.; Kikkawa, J. M.; Forrest, W. P.; Christensen, C. N.; Schwarz, D. E.; Fanwick, P. E.; Clark, D. L.; Conradson, S. D.; Bart, S. C., Synthesis, Characterization, and Multielectron Reduction Chemistry of Uranium Supported by Redox-Active alpha-Diimine Ligands. Inorg. Chem. 2011, 50, 9838-9848; (h) Schelter, E. J.; Wu, R. L.; Scott, B. L.; Thompson, J. D.; Cantat, T.; John, K. D.; Batista, E. R.; Morris, D. E.; Kiplinger, J. L., Actinide Redox-Active Ligand Complexes: Reversible Intramolecular Electron-Transfer in U(dppBIAN $)_{2} / \mathrm{U}(\mathrm{dpp}-\mathrm{BIAN})_{2}$ (THF). Inorg. Chem. 2010, 49, 924-933; (i) Kraft, S. J.; Fanwick, P. E.; Bart, S. C., Synthesis and Characterization of a Uranium(III) Complex Containing a RedoxActive 2,2 '-Bipyridine Ligand. Inorg. Chem. 2010, 49, 1103-1110. 4. (a) Barluzzi, L.; Falcone, M.; Mazzanti, M., Small molecule activation by multimetallic uranium complexes supported by siloxide ligands. Chem. Commun. 2019, 55, 13031--13047; (b) Falcone, M.; Chatelain, L.; Scopelliti, R.; Zivkovic, I.; Mazzanti, M., Nitrogen reduction and functionalization by a multimetallic uranium nitride complex. Nature 2017, 547, 332-335; (c) Camp, C.; Pecaut, J.; Mazzanti, M., Tuning Uranium-Nitrogen Multiple Bond Formation with Ancillary Siloxide Ligands. J. Am. Chem. Soc. 2013 , 135, 12101-12111; (d) Cooper, O.; Camp, C.; Pécaut, J.; Kefalidis, C. E.; Maron, L.; Gambarelli, S.; Mazzanti, M., Multimetallic Cooperativity in Uranium-Mediated $\mathrm{CO}_{2}$ Activation. J. Am. Chem. Soc. 2014, 136, 6716-6723; (e) Evans, W. J.; Kozimor, S. A., Expanding the chemistry of $\mathrm{U} 3+$ reducing agents. Coord. Chem. Rev. 2006, 250, 911-935; (f) Bart, S. C.; Meyer, K., Highlights in uranium coordination chemistry. In Struct. Bond., 2008; Vol. 127, pp 119-176; (g) Bart, S. C.; Anthon, C.; Heinemann, F. W.; Bill, E.; Edelstein, N. M.; Meyer, K., Carbon dioxide activation with sterically pressured mid- and high-valent uranium complexes. J. Am. Chem. Soc. 2008, 130, 12536-12546; (h) Warner, B. P.; Scott, B. L.; Burns, C. J., A simple preparative route to bis(imido)-uranium(VI) complexes by the direct reductions of diazenes and azides. Angew. Chem. Int. Ed. Engl. 1998, 37, 959-960.

5. (a) Cladis, D. P.; Kiernicki, J. J.; Fanwick, P. E.; Bart, S C., Multi-electron reduction facilitated by a trianionic pyridine(diimine) ligand. Chem. Commun. 2013, 49, 4169-4171; (b) Zi, G. F.; Jia, L.; Werkema, E. L.; Walter, M. D.; Gottfriedsen, J. P.; Andersen, R. A., Preparation and reactions of base-free bis(1,2,4-tritert-butylcyclopentadienyl)uranium oxide, $\mathrm{Cp}_{2}^{\prime} \mathrm{UO}$. Organometallics 2005, 24, 4251-4264; (c) Zi, G. F.; Blosch, L. L.; Jia, L.; Andersen, R. A., Preparation and reactions of base-free bis (1,2,4-tri-tertbutylcyclopentadienyl) uranium methylimide, $\mathrm{C}_{\mathrm{P}}{ }^{\prime} \mathrm{U}_{2}=\mathrm{NMe}$, and related compounds. Organometallics 2005, 24, 4602-4612; (d) Evans, W. J.; Kozimor, S. A.; Ziller, J. W., $\left(\mathrm{C}_{5} \mathrm{Me}_{5}\right)_{2} \mathrm{U}(\mathrm{mu}-\mathrm{Ph})_{2} \mathrm{BPh}_{2}$ as a four electron reductant. Chem. Commun. 2005, 4681-4683; (e) Diaconescu, P. L.; Arnold, P. L.; Baker, T. A.; Mindiola, D. J.; Cummins, C. C., Arene-bridged diuranium complexes: Inverted sandwiches supported by delta backbonding. J. Am. Chem. Soc. 2000, 122, 6108-6109.

6. (a) Coughlin, E. J.; Qiao, Y. S.; Lapsheva, E.; Zeller, M.; Schelter, E. J.; Bart, S. C., Uranyl Functionalization Mediated by Redox-Active Ligands: Generation of O-C Bonds via Acylation. J. Am. Chem. Soc. 2019, 141, 1016-1026; (b) Kiernicki, J. J.; Cladis, D. 
P.; Fanwick, P. E.; Zeller, M.; Bart, S. C., Synthesis, Characterization, and Stoichiometric U-O Bond Scission in Uranyl Species Supported by Pyridine(diimine) Ligand Radicals. J. Am. Chem. Soc. 2015, 137, 11115-11125.

7. (a) Fang, H. Y.; Cole, B. E.; Qiao, Y. S.; Bogart, J. A.; Cheisson, T.; Manor, B. C.; Carroll, P. J.; Schelter, E. J., Electrokinetic Separation of Rare Earth Elements Using a Redox-Active Ligand. Angew. Chem. Int. Ed. Engl. 2017, 56, 13450-13454; (b) Vasudevan, K.; Cowley, A. H., Synthesis and structures of 1,2bis(imino)acenaphthene (BIAN) lanthanide complexes that involve the transfer of zero, one, or two electrons. Chem. Commun. 2007, 3464-3466; (c) Camp, C.; Guidal, V.; Biswas, B.; Pecaut, J.; Dubois, L.; Mazzanti, M., Multielectron redox chemistry of lanthanide Schiffbase complexes. Chem. Sci. 2012, 3, 2433-2448; (d) Coughlin, E. J.; Zeller, M.; Bart, S. C., Neodymium(III) Complexes Capable of MultiElectron Redox Chemistry. Angew. Chem. Int. Ed. Engl. 2017, 56, 12142-12145.

8. (a) Camp, C.; Andrez, J.; Pecaut, J.; Mazzanti, M., Synthesis of Electron-Rich Uranium(IV) Complexes Supported by Tridentate Schiff Base Ligands and Their Multi-Electron Redox Chemistry. Inorg. Chem. 2013, 52, 7078-7086; (b) Evans, W. J.; Montalvo, E.; Kozimor, S. A.; Miller, K. A., Multi-electron reduction from alkyl/hydride ligand combinations in $\mathrm{U}^{4+}$ complexes. $J$. Am. Chem. Soc. 2008, 130, 12258-12259; (c) Niklas, J. E.; Hardy, E. E.; Gorden, A. E. V., Solid-state structural elucidation and electrochemical analysis of uranyl naphthylsalophen. Chem. Commun. 2018, 54; (d) Niklas, J. E.; Farnum, B. H.; Gorden, J. D.; Gorden, A. E. V., Structural Characterization and Redox Activity of a Uranyl Dimer and Transition-Metal Complexes of a Tetradentate BIAN Ligand. Organometallics 2017, 36, 4626-4634.

9. (a) DeAngelis, S.; Solari, E.; Gallo, E.; Floriani, C.; ChiesiVilla, A.; Rizzoli, C., Formation of carbon-carbon-bonded dimers in the reduction of [Co(II)salophen] [salophen equals N,N'-ophenylenebis(salicylideneaminato)]: Their reactivity with electrophiles to form Co-C bonds. Inorg. Chem. 1996, 35, 5995-6003; (b) Franceschi, F.; Solari, E.; Scopelliti, R.; Floriani, C., Metalmediated transfer of electrons between two different C-C single bonds that function as electron-donor and electron-acceptor units. Angew. Chem. Int. Ed. Engl. 2000, 39, 1685-1686; (c) Floriani, C.; Solari, E.; Franceschi, F.; Scopelliti, R.; Belanzoni, P.; Rosi, M., Metal-metal and carbon-carbon bonds as potential components of molecular batteries. Chem. Eur. J. 2001, 7, 3052-3061; (d) Solari, E.; Maltese, C.; Franceschi, F.; Floriani, C.; ChiesiVilla, A.; Rizzoli, C., Geometrical isomerism and redox behaviour in zirconium-Schiff base complexes: the formation of C-C bonds functioning as twoelectron reservoirs. J. Chem. Soc., Dalton Trans. 1997, 2903-2910; (e) Gambarotta, S.; Mazzanti, M.; Floriani, C.; Zehnder, M., A Tetranuclear Polyfunctional Sodium-Vanadium(III) Complex Containing a Vanadium(III-Vanadium(III) Double-Bond. J. Chem. Soc., Chem. Commun. 1984, 1116-1118.

10. (a) Dalla Cort, A.; Pasquini, C.; Schiaffino, L., Nonsymmetrically substituted uranyl-salophen receptors: New opportunities for molecular recognition and catalysis. Supramol. Chem. 2007, 19, 79-87; (b) Bharara, M. S.; Strawbridge, K.; Vilsek, J. Z.; Bray, T. H.; Gorden, A. E. V., Novel dinuclear uranyl complexes with asymmetric Schiff base ligands: Synthesis, structural characterization, reactivity, and extraction studies. Inorg. Chem. 2007, 46, 8309-8315; (c) Gaunt, A. J.; Jones, M. B., Recent Developments in Synthesis and Structural Chemistry of Nonaqueous Actinide Complexes. Chem. Rev. 2013, 113, 1137-1198; (d) Sessler, J. L.; Melfi, P. J.; Pantos, G. D., Uranium complexes of multidentate N-donor ligands. Coord. Chem. Rev. 2006, 250, 816-843.

11. (a) Faizova, R.; White, S.; Scopelliti, R.; Mazzanti, M., The effect of iron binding on uranyl(v) stability. Chem. Sci. 2018, 9 , 7520-7527; (b) Mougel, V.; Pecaut, J.; Mazzanti, M., New polynuclear U(IV)-U(V) complexes from U(IV) mediated uranyl(V) disproportionation. Chem. Commun. 2012, 48, 868-870; (c) Nocton, G.; Horeglad, P.; Vetere, V.; Pécaut, J.; Dubois, L.; Maldivi, P.; Edelstein, N. M.; Mazzanti, M., Synthesis, Structure, and Bonding of Stable Complexes of Pentavalent Uranyl. J. Am. Chem. Soc. 2010, 132, 495-508; (d) Mougel, V.; Horeglad, P.; Nocton, G.; Pecaut, J.; Mazzanti, M., Stable Pentavalent Uranyl Species and Selective Assembly of a Polymetallic Mixed-Valent Uranyl Complex by
Cation-Cation Interactions. Angew. Chem. Int. Ed. Engl. 2009, 48, 8477-8480; (e) Cowie, B. E.; Purkis, J. M.; Austin, J.; Love, J. B.; Arnold, P. L., Thermal and Photochemical Reduction and Functionalization Chemistry of the Uranyl Dication, $\left(\mathrm{UO}_{2}\right)-\mathrm{O}-\mathrm{VI}$ (2+). Chem. Rev. 2019, 119, 10595-10637.

12. (a) Klamm, B. E.; Windorff, C. J.; Ceis-Barros, C.; Marsh, M. L.; Meeker, D. S.; Albrecht-Schmitt, T. E., Experimental and Theoretical Comparison of Transition-Metal and Actinide Tetravalent Schiff Base Coordination Complexes. Inorg. Chem. 2018, 57, 15389 15398; (b) Camp, C.; Chatelain, L.; Mougel, V.; Pecaut, J.; Mazzanti, M., Ferrocene-Based Tetradentate Schiff Bases as Supporting Ligands in Uranium Chemistry. Inorg. Chem. 2015, 54, 5774-5783; (c) Arnold, P. L.; Potter, N. A.; Carmichael, C. D.; Slawin, A. M. Z.; Roussel, P.; Love, J. B., Constructing cerium supramolecular wheels and encapsulating uranium with a Schiff-base calixpyrrole ligand. Chem. Commun. 2010, 46, 1833-1835.

13. (a) Salmon, L.; Thuery, P.; Ephritikhine, M., Synthesis and crystal structure of tetra-and hexanuclear uranium(IV) complexes with hexadentate compartmental Schiff-base ligands. J. Chem. Soc.Dalton Trans. 2004, 4139-4145; (b) Le Borgne, T.; Riviere, E.; Marrot, J.; Girerd, J. J.; Ephritikhine, M., Synthesis, crystal structure, and magnetic behavior of linear M-2(II)U(IV) complexes ( $\mathrm{M}=\mathrm{Co}$, $\mathrm{Ni}, \mathrm{Cu}, \mathrm{Zn}$ ). Angew. Chem. Int. Ed. Engl. 2000, 39, 1647-1649; (c) Dame, A. N.; Bharara, M. S.; Barnes, C. L.; Walensky, J. R., Synthesis of Thorium(IV) and Uranium(IV) Salicylaldiminate Pseudo-Halide Complexes. Eur. J. Inorg. Chem. 2015, 2996-3005.

14. (a) Andrez, J.; Guidal, V.; Scopelliti, R.; Pecaut, J.; Gambarelli, S.; Mazzanti, M., Ligand and Metal Based Multielectron Redox Chemistry of Cobalt Supported by Tetradentate Schiff Bases. J. Am. Chem. Soc. 2017, 139, 8628-8638; (b) Solomon, M. B.; Chan, B.; Kubiak, C. P.; Jolliffe, K. A.; D'Alessandro, D. M., The spectroelectrochemical behaviour of redox-active manganese salen complexes. J. Chem. Soc.-Dalton Trans. 2019, 48, 3704-3713; (c) Nichols, A. W.; Chatterjee, S.; Sabat, M.; Machan, C. W., Electrocatalytic Reduction of $\mathrm{CO}_{2}$ to Formate by an Iron Schiff Base Complex. Inorg. Chem. 2018, 57, 2111-2121.

15. Mandal, S.; Seth, D. K.; Gupta, P., Encapsulating ruthenium and osmium with tris(2-aminoethyl)amine based tripodal ligands. Polyhedron 2012, 31, 167-175.

16. Matin, S. J.; Khojasteh, R. R., Synthesis, characterization, and antibacterial activities of $\mathrm{Cr}(\mathrm{III}), \mathrm{Co}(\mathrm{III}), \mathrm{Ni}(\mathrm{II})$, and $\mathrm{Mn}(\mathrm{III})$ complexes of heptadentate Schiff base ligand derived from tris(2aminoethyl)amine. Russ. J. Gen. Chem. 2015, 85, 1763-1767.

17. Avens, L. R.; Bott, S. G.; Clark, D. L.; Sattelberger, A. P.; Watkin, J. G.; Zwick, B. D., A convenient entry into trivalent actinide chemistry: Synthesis and characterization of $\mathrm{AnI}_{3}(\text { thf })_{4}$ and $\mathrm{An}\left(\mathrm{N}\left(\mathrm{SiMe}_{3}\right)_{2}\right)_{3}(\mathrm{An}=\mathrm{U}, \mathrm{Np}, \mathrm{Pu})$. Inorg. Chem. 1994, 33, 2248-2256. 18. Kiplinger, J. L.; Morris, D. E.; Scott, B. L.; Burns, C. J., Convenient synthesis, structure, and reactivity of $\left(\mathrm{C}_{5} \mathrm{Me}_{5}\right) \mathrm{U}\left(\mathrm{CH}_{2} \mathrm{C}_{6} \mathrm{H}_{5}\right)(3)$ : a simple strategy for the preparation of monopentamethylcyclopentadienyl uranium(IV) complexes. Organometallics 2002, 21, 5978-5982.

19. Carmichael, C. D.; Jones, N. A.; Arnold, P. L., Low-valent uranium iodides: Straightforward solution syntheses of UI(3) and UI(4) etherates. Inorg. Chem. 2008, 47, 8577-8579.

$20 . \quad$ (a) Andrez, J.; Pecaut, J.; Bayle, P.-A.; Mazzanti, M., Tuning Lanthanide Reactivity Towards Small Molecules with Electron-Rich Siloxide Ligands. Angew. Chem. Int. Ed. Engl. 2014, 53, 10448-10452; (b) Camp, C.; Cooper, O.; Andrez, J.; Pecaut, J.; Mazzanti, M., $\mathrm{CS}_{2}$ activation at uranium(III) siloxide ate complexes: the effect of a Lewis acidic site. J. Chem. Soc.-Dalton Trans. 2015, 44, 2650-2656.

21. Duisenberg, A. J. M.; Kroon-Batenburg, L. M. J.; Schreurs, A. M. M., An intensity evaluation method: EVAL-14. J. Appl. Crystallogr. 2003, 36, 220-229.

22. Blessing, R. H., An empirical correction for absorption anisotropy. Acta Crystallogr., Sect. A 1995, 51, 33-38.

23. CrysAlisPRO, Rigaku Oxford Diffraction 2018.

24. Sheldrick, G. M., SHELXT - Integrated space-group and crystal-structure determination. Acta Cryst. a-Foundation and Advances 2015, 71, 3-8.

25. Sheldrick, G. M., Crystal structure refinement with SHELXL. Acta Crystallogr. C 2015, 71, 3-8. 
26. PLATON; Spek, A. L., Structure validation in chemical crystallography. Acta Cryst. D 2009, 65, 148-155.

27. (a) Berthet, J. C.; Ephritikhine, M., New advances in the chemistry of uranium amide compounds. Coord. Chem. Rev. 1998, 178, 83-116; (b) Seaman, L. A.; Fortier, S.; Wu, G. A.; Hayton, T. W., Comparison of the Redox Chemistry of Primary and Secondary Amides of U(IV): Isolation of a U(VI) Bis(imido) Complex or a Homoleptic U(VI) Amido Complex. Inorg. Chem. 2011, 50, 636-646. 28. Maury, O.; Villiers, C.; Ephritikhine, M., Metallopinacolate intermediates in the reductive coupling of acetone promoted by uranium reagents. Angew. Chem. Int. Ed. Engl. 1996, $35,1129-1130$.

29. Summerscales, O. T.; Cloke, F. G. N.; Hitchcock, P. B.; Green, J. C.; Hazari, N., Reductive cyclotrimerization of carbon monoxide to the deltate dianion by an organometallic uranium complex. Science 2006, 311, 829-831.

30. Lam, O. P.; Heinemann, F. W.; Meyer, K., C-C Bond Formation through Reductive Coupling of $\mathrm{CS}_{2}$ to Yield Uranium Tetrathiooxalate and Ethylenetetrathiolate Complexes. Angew. Chem. Int. Ed. Engl. 2011, 50, 5965-5968.

31. (a) Arduini, A. L.; Jamerson, J. D.; Takats, J., Reactivity of dicyclopentadienylbis(diethylamido)uranium(iv) - insertion reactions. Inorg. Chem. 1981, 20, 2474-2479; (b) Frey, J. A. H.; Cloke, G. N.; Roe, S. M., Organometallics 2015, 34, 2102-2105

; (c) Matson, E. M.; Fanwick, P. E.; Bart, S. C., Formation of Trivalent $\mathrm{U}-\mathrm{C}, \mathrm{U}-\mathrm{N}$, and U-S Bonds and Their Reactivity toward Carbon Dioxide and Acetone. Organometallics 2011, 30, 5753-5762.

32. (a) Mougel, V.; Camp, C.; Pecaut, J.; Coperet, C.; Maron, L.; Kefalidis, C. E.; Mazzanti, M., Siloxides as Supporting Ligands in Uranium(III)-Mediated Small-Molecule Activation. Angew. Chem. Int. Ed. Engl. 2012, 51, 12280-12284; (b) Lam, O. P.; Meyer, K., Uranium-mediated carbon dioxide activation and functionalization. Polyhedron 2012, 32, 1-9; (c) Castro, L.; Lam, O. P.; Bart, S. C.; Meyer, K.; Maron, L., Carbonate Formation from $\mathrm{CO} 2$ via Oxo versus Oxalate Pathway: Theoretical Investigations into the Mechanism of Uranium-Mediated Carbonate Formation. Organometallics 2010, 29, 5504-5510; (d) Castro-Rodriguez, I.; Meyer, K., Carbon dioxide reduction and carbon monoxide activation employing a reactive uranium(III) complex. J. Am. Chem. Soc. 2005, $127,11242-11243$.
33. Fagan, P. J.; Manriquez, J. M.; Vollmer, S. H.; Day, C. S.; Day, V. W.; Marks, T. J., Insertion of carbon-monoxide into metalnitrogen bonds - synthesis, chemistry, structures, and structural dynamics of bis(pentamethylcyclopentadienyl) organoactinide dialkylamides and eta-2-carbamoyls. J. Am. Chem. Soc. 1981, 103, 2206-2220.

34. Du, H. F.; Zhao, B. G.; Shi, Y., Catalytic asymmetric allylic and homoallylic diamination of terminal olefins via formal $\mathrm{C}-\mathrm{H}$ activation. J. Am. Chem. Soc. 2008, 130, 8590-+.

35. (a) Camp, C.; Antunes, M. A.; Garcia, G.; Ciofini, I.; Santos, I. C.; Pecaut, J.; Almeida, M.; Marcalo, J.; Mazzanti, M., Two-electron versus one-electron reduction of chalcogens by uranium(III): synthesis of a terminal U(V) persulfide complex. Chem. Sci. 2014, 5, 841-846; (b) Rosenzweig, M. W.; Scheurer, A.; Lamsfus, C. A.; Heinemann, F. W.; Maron, L.; Andrez, J.; Mazzanti, M.; Meyer, K., Uranium(IV) terminal hydrosulfido and sulfido complexes: insights into the nature of the uranium-sulfur bond. Chem. Sci. 2016, 7, 5857-5866; (c) Schmidt, A.-C.; Heinemann, F. W.; Lukens, W. W., Jr.; Meyer, K., Molecular and Electronic Structure of Dinuclear Uranium Bis-mu-Oxo Complexes with Diamond Core Structural Motifs. J. Am. Chem. Soc. 2014, 136, 11980-11993; (d) Morris, D. E.; Da Re, R. E.; Jantunen, K. C.; Castro-Rodriguez, I.; Kiplinger, J. L., Trends in electronic structure and redox energetics for earlyactinide pentamethylcyclopentadienyl complexes. Organometallics 2004, 23, 5142-5153; (e) Schelter, E. J.; Yang, P.; Scott, B. L.; Thompson, J. D.; Martin, R. L.; Hay, P. J.; Morris, D. E.; Kiplinger, J. L., Systematic studies of early actinide complexes: Uranium(IV) fluoroketimides. Inorg. Chem. 2007, 46, 7477-7488; (f) Graves, C. R.; Yang, P.; Kozimor, S. A.; Vaughn, A. E.; Clark, D. L.; Conradson, S. D.; Schelter, E. J.; Scott, B. L.; Thompson, J. D.; Hay, P. J.; Morris, D. E.; Kiplinger, J. L., Organometallic uranium(V)-imido halide complexes: From synthesis to electronic structure and bonding. $J$. Am. Chem. Soc. 2008, 130, 5272-5285.

36. Camp, C. Design and reactivity of monoand polymetallic complexes of low-valent f-elements. Universite de Grenoble, Grenoble, France, 2013.

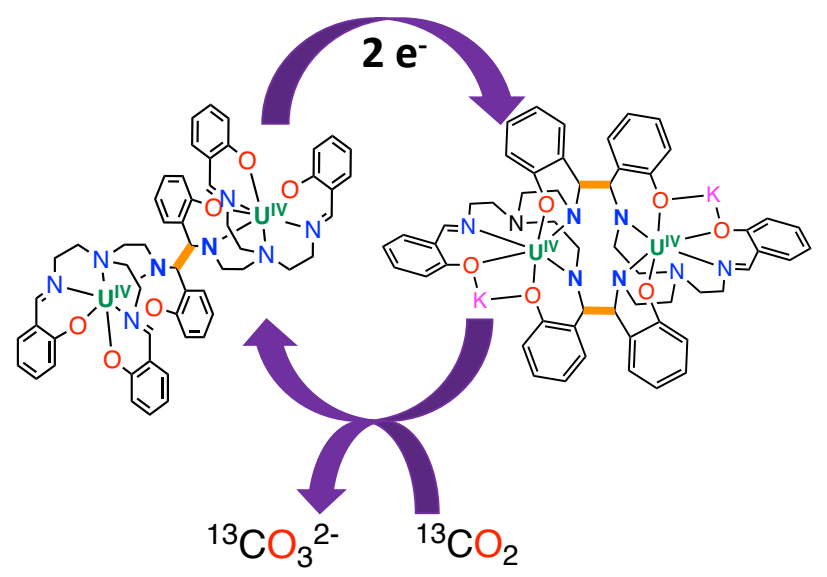

